\title{
Nanosized Spinel Ferrites Synthesized by Sol-Gel Autocombustion for Optimized Removal of Azo Dye from Aqueous Solution
}

\author{
Petrisor Samoila, ${ }^{1}$ Corneliu Cojocaru, ${ }^{1}$ Igor Cretescu, ${ }^{2}$ Catalina Daniela Stan, ${ }^{3}$ \\ Valentin Nica, ${ }^{4}$ Liviu Sacarescu, ${ }^{1}$ and Valeria Harabagiu ${ }^{1}$ \\ 1 "Petru Poni" Institute of Macromolecular Chemistry, Aleea Grigore Ghica Voda 41 A, 700487 Iasi, Romania \\ ${ }^{2}$ Department of Environmental Engineering and Management, "Gheorghe Asachi" Technical University of Iasi, \\ 73 Dimitrie Mangeron Street, 700050 Iasi, Romania \\ ${ }^{3}$ Department of Drug Industry and Pharmaceutical Biotechnology, "Grigore T. Popa" University of Medicine and Pharmacy, \\ 16 University Street, 700115 Iasi, Romania \\ ${ }^{4}$ Faculty of Physics, “Alexandru Ioan Cuza" University, No. 11, Carol I Boulevard, 700506 Iasi, Romania
}

Correspondence should be addressed to Igor Cretescu; icre1@yahoo.co.uk and Catalina Daniela Stan; catalinastan68@yahoo.com

Received 30 March 2015; Accepted 27 April 2015

Academic Editor: Praveen K. Sekhar

Copyright (C) 2015 Petrisor Samoila et al. This is an open access article distributed under the Creative Commons Attribution License, which permits unrestricted use, distribution, and reproduction in any medium, provided the original work is properly cited.

Nanosized spinel ferrites $\mathrm{MFe}_{2} \mathrm{O}_{4}(\mathrm{M}=\mathrm{Ni}, \mathrm{Co}$, and $\mathrm{Zn})$ have been prepared by sol-gel autocombustion method using citric acid as a fuel agent. The materials are characterized by X-ray diffraction (XRD), Fourier transform infrared spectroscopy (FTIR), and transmission electron microscopy (TEM). The spinel ferrites have been applied for Congo-Red (CR) dye adsorption using batch technique. Different kinetic and equilibrium models have been fitted by nonlinear regression to analyze the adsorption data. In accordance with Langmuir isotherm, the maximum adsorption capacity at $293 \mathrm{~K}$ is $14.06 \mathrm{mg} / \mathrm{g}$ for $\mathrm{CoFe}_{2} \mathrm{O}_{4}$ and $17.13 \mathrm{mg} / \mathrm{g}$ for $\mathrm{NiFe}_{2} \mathrm{O}_{4}$. The values of mean free energy determined from Dubinin-Radushkevich isotherm are higher than $8\left(\mathrm{~kJ} \mathrm{~mol}^{-1}\right)$, indicating a chemisorption mechanism. Based on the calculated thermodynamic parameters (free energy, enthalpy, and entropy) the adsorption of CR onto ferrites is a spontaneous and endothermic process. Response surface methodology has been applied to construct the multiple regression models for prediction of the adsorption capacity and removal efficiency. The model-based optimization has been performed using genetic algorithms and desirability function approach. The single-objective optimization has yielded a maximum value of color removal efficiency of $98.995 \%$, using $\mathrm{NiFe}_{2} \mathrm{O}_{4}$ adsorbent. The multiobjective optimization has resulted in the improvement of both removal efficiency and adsorption capacity.

\section{Introduction}

The azo dyes are extensively employed as coloring agents in the industries such as textile, paper, plastic, leather, cosmetics, photographic industries, and biomedical industries. A significant part of the total amount of dyes (about 15\%) are lost and discharged into the environment during dye production and dying processes [1-3]. Numerous research reports proved that azo dyes are toxic, mutagenic, and carcinogenic compounds [4].

Different physical, chemical, and biological methods have been used to remove dyes from industrial effluents [4-6].
Among physical methods, adsorption is very often employed for effective treatment of wastewater. The adsorption consists in attaching of soluble pollutants on a solid material (organic or inorganic support). Therefore, different sorbents such as activated carbon, coal, fly ash, clays, silica, alumina, and chitosan have been employed in dye adsorption studies [5]. Despite their good adsorption performances, the separation and recovery of these adsorbents from heterogeneous systems still remain a drawback. Recently, the magnetic separation technology has attracted attention as a feasible alternative for traditional separation technologies such as settling, centrifugation, or membrane filtration [7, 8]. In this line, ferrites 
were proposed as potential adsorbents for dyes removal due to their appropriate physical characteristics and facile separation under external magnetic fields [7-11].

In the present study, Congo-Red (CR) has been used to evaluate the adsorption capacity of three representative magnetic spinel ferrites with the general formula $\mathrm{MFe}_{2} \mathrm{O}_{4}$ $(\mathrm{M}=\mathrm{Ni}, \mathrm{Co}$, and $\mathrm{Zn})$, obtained as nanosized particles by sol-gel autocombustion method. The adsorption of CR has been investigated via kinetics, equilibrium, and thermodynamic approaches. Special attention has been devoted to the response surface modeling and optimization of the adsorption process to enhance the dye removal efficiency.

\section{Materials and Methods}

2.1. Materials. Analytical grade $\mathrm{Ni}\left(\mathrm{NO}_{3}\right)_{2} \cdot 6 \mathrm{H}_{2} \mathrm{O}, \mathrm{Co}\left(\mathrm{NO}_{3}\right)_{2}$ $\cdot 6 \mathrm{H}_{2} \mathrm{O}, \mathrm{Zn}\left(\mathrm{NO}_{3}\right)_{2} \cdot 6 \mathrm{H}_{2} \mathrm{O}, \mathrm{Fe}\left(\mathrm{NO}_{3}\right)_{3} \cdot 9 \mathrm{H}_{2} \mathrm{O}$, citric acid monohydrate, and Congo-Red azo dye were purchased from Sigma-Aldrich and used without further purification.

2.2. Synthesis of Nanosized Spinel Ferrites Sorbents. $\mathrm{MFe}_{2} \mathrm{O}_{4}$ $(\mathrm{M}=\mathrm{Ni}, \mathrm{Co}$, and $\mathrm{Zn})$ spinel ferrite materials were prepared by sol-gel autocombustion method [12]. In a typical experiment, stoichiometric amounts of metal nitrates were dissolved in distilled water with the molar ratio $\mathrm{M}^{2+} / \mathrm{Fe}^{3+}$ of $1: 2$. The molar ratio of metallic cations to citric acid was $1: 1$. The aqueous solution of citric acid was added to the solution of nitrate salts and heated to $353 \mathrm{~K}$ on a water bath under stirring until a viscous gel was formed. The gel was gradually heated to $623 \mathrm{~K}$ when the autoignition was clearly observed. The resulting powder was sintered in two steps (at $773 \mathrm{~K} / 5 \mathrm{~h}$ and at $973 \mathrm{~K} / 5 \mathrm{~h}$ ) in order to achieve the spinel phase formation.

2.3. Characterization Techniques. XRD patterns of the powder samples sintered at $973 \mathrm{~K}$ were recorded using a Shimadzu LabX 6000 diffractometer equipped with graphite monochromator and $\mathrm{CuK} \alpha(\lambda=0.15406 \mathrm{~nm})$ radiation. The samples were scanned from 20 to $80^{\circ}(2 \theta)$ using a scanning rate of $0.02^{\circ} / \mathrm{s}$.

The formation of spinel phase of $\mathrm{MFe}_{2} \mathrm{O}_{4}$ ferrite was monitored by infrared spectroscopy in $4000-350 \mathrm{~cm}^{-1}$ range using a Bruker Vertex 70 FTIR spectrometer with a resolution of $2 \mathrm{~cm}^{-1}$ ( $\mathrm{KBr}$ pellets technique).

The morphology and microstructure of ferrite samples sintered at $973 \mathrm{~K}$ were investigated using Hitachi HighTech HT7700 transmission electron microscope, operated at $100 \mathrm{kV}$ accelerating voltage in high-contrast mode.

2.4. Adsorption Experiments. A stock solution of $200 \mathrm{mg} / \mathrm{L}$ was prepared by dissolving CR in distilled water. The working solutions were prepared by diluting the stock solution to the desired concentrations. The concentrations of CR in the solutions were analyzed using UV-Vis spectrophotometer (Shimadzu UV-1700 PharmaSpec) by monitoring the absorbance at the wavelength of $\lambda_{\max }=497 \mathrm{~nm}$.

The prepared ferrites were applied as adsorbents for the removal of CR from the aqueous solutions using the batch technique. For this purpose, calculated amounts of

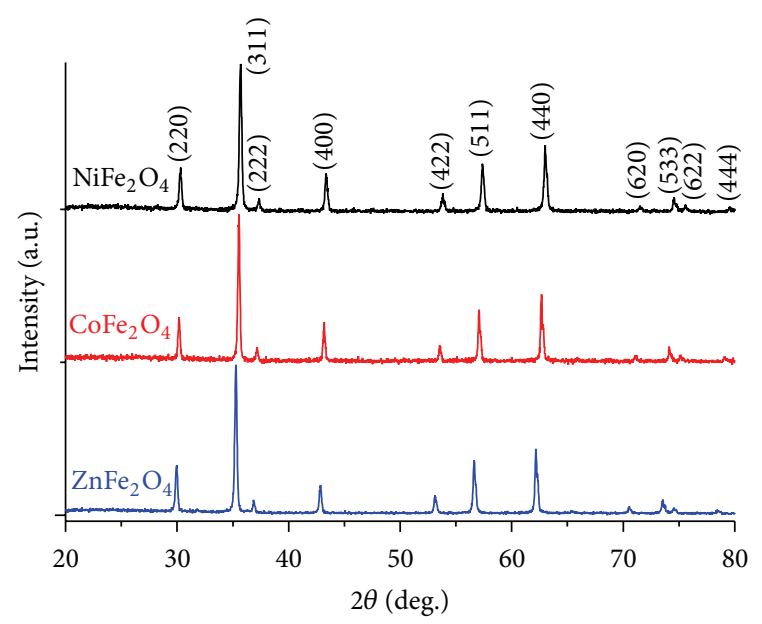

FIGURE 1: XRD patterns of $\mathrm{MFe}_{2} \mathrm{O}_{4}(\mathrm{M}=\mathrm{Ni}, \mathrm{Co}$, and $\mathrm{Zn})$ spinel ferrites.

adsorbents were added to $50 \mathrm{~mL}$ of working solutions, and the samples were magnetically stirred at $500 \mathrm{rpm}$ for different periods of time. The adsorption experiments were carried out at naturally occurring $\mathrm{pH} 6.80$ and at the different temperatures (i.e., $293 \mathrm{~K}, 313 \mathrm{~K}$, and $333 \mathrm{~K}$ ). At the end of the adsorption tests the loaded ferrites were separated using a magnet, and the resulting clear solutions were analyzed for CR concentrations. In all the experiments (screening test, kinetics, isotherms, and optimization) the adsorption capacity was determined using the following equation [13]:

$$
q=\frac{\left(C_{0}-C\right) \cdot V}{m \cdot 1000}
$$

where $q$ denotes the adsorption capacity $(\mathrm{mg} / \mathrm{g}), C_{0}$ is the initial concentration of $\mathrm{CR}$ in solution $(\mathrm{mg} / \mathrm{L}), C$ is the final concentration of CR in solution $(\mathrm{mg} / \mathrm{L}), V$ is the volume of solution (mL), and $m$ represents the weight of the adsorbent (g). In addition, the color removal efficiency $Y(\%)$ was determined by subsequent equation $[13,14]$ :

$$
Y=\left(1-\frac{C}{C_{0}}\right) \times 100
$$

\section{Results and Discussion}

3.1. Characterization of $\mathrm{MFe}_{2} \mathrm{O}_{4}$ Spinel Ferrites Sorbents. Xray diffraction patterns of $\mathrm{MFe}_{2} \mathrm{O}_{4}(\mathrm{M}=\mathrm{Ni}, \mathrm{Co}$, and $\mathrm{Zn})$ spinel ferrites are shown in Figure 1. For all the analyzed materials, the most intense peaks characteristic for spinel structure were observed at $2 \theta$ of about $35^{\circ}$. All peaks observed in the XRD patterns correspond to the face-centered cubic structure of pure spinels according to JCPDS cards number 44-1485, number 22-1086, and number 22-1012.

The crystallite size $\left(D_{c}, \mathrm{~nm}\right)$ for each sample was calculated by line broadening of the most intense (311) diffraction peak using Debye-Scherrer formula [7] (see Table 1). According to Table 1, the values of crystallite size depend on $\mathrm{M}^{2+}$ cation nature. The smallest nanosized crystallite 
TABLE 1: Summary of the experimental and calculated data obtained for $\mathrm{MFe}_{2} \mathrm{O}_{4}(\mathrm{M}=\mathrm{Ni}, \mathrm{Co}$, and $\mathrm{Zn})$ spinel ferrites.

\begin{tabular}{lccc}
\hline Spinel ferrite & ${ }^{\mathrm{a}} 2 \theta_{311}$ (degrees) & ${ }^{\mathrm{a}} D_{c}(\mathrm{~nm})$ & ${ }^{\mathrm{b}}\left\langle d_{p}\right\rangle(\mathrm{nm})$ \\
\hline $\mathrm{NiFe}_{2} \mathrm{O}_{4}$ & 35.68803 & 30.6 & 46 \\
$\mathrm{CoFe}_{2} \mathrm{O}_{4}$ & 35.53905 & 36.7 & 69 \\
$\mathrm{ZnFe}_{2} \mathrm{O}_{4}$ & 35.27044 & 34.4 & 101 \\
\hline
\end{tabular}

${ }^{\mathrm{a}}$ Diffraction angle $\left(\theta_{311}\right)$ and crystallite size $\left(D_{c}\right)$, data from XRD; ${ }^{\mathrm{b}}$ particle size, data from TEM.

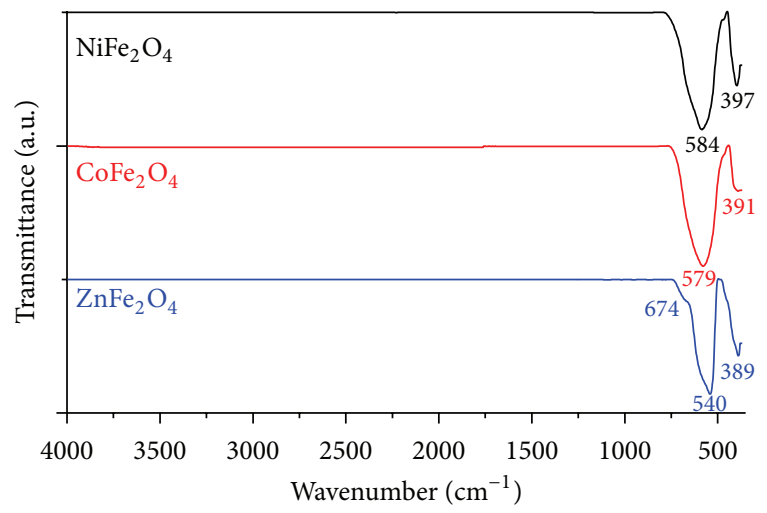

FIgURE 2: FTIR spectra of $\mathrm{MFe}_{2} \mathrm{O}_{4}(\mathrm{M}=\mathrm{Ni}, \mathrm{Co}$, and $\mathrm{Zn})$ spinel ferrites.

value was found for nickel ferrite $(30.6 \mathrm{~nm})$, followed by zinc ferrite $(34.4 \mathrm{~nm})$, and cobalt containing ferrite $(36.7 \mathrm{~nm})$, respectively.

The FTIR spectra, in 4000-350 $\mathrm{cm}^{-1}$ range for $\mathrm{MFe}_{2} \mathrm{O}_{4}$ $(\mathrm{M}=\mathrm{Ni}, \mathrm{Co}$, and $\mathrm{Zn})$ powders heated at $973 \mathrm{~K}$ are shown in Figure 2. The FTIR spectra revealed only the specific bands for metal-oxygen stretching vibration from the tetrahedral site in 584-540 $\mathrm{cm}^{-1}$ range and from the octahedral site at $397-389 \mathrm{~cm}^{-1}$. Careful observation of the $\mathrm{ZnFe}_{2} \mathrm{O}_{4}$ IR spectra shows a supplementary third absorption band at $674 \mathrm{~cm}^{-1}$. The presence of this band is explained by the cation exchange between the tetrahedral and octahedral spinel sites which often occurs for zinc ferrite [15].

The representative TEM micrographs of $\mathrm{MFe}_{2} \mathrm{O}_{4}$ samples are illustrated in Figure 3.

The average particle sizes $\left(\left\langle d_{p}\right\rangle, \mathrm{nm}\right)$ determined from microscopy images (TEM) are reported in Table 1 . For all three studied materials, TEM images prove the formation of soft agglomerates constituted of nanosized particles with irregular (nanopolyhedra) shapes. The average sizes of individual particles are of $46 \mathrm{~nm}, 69 \mathrm{~nm}$, and $101 \mathrm{~nm}$ for nickel, cobalt, and zinc ferrites, respectively (Table 1). Note that from XRD patterns only crystallites sizes can be evaluated. In turn, the microscopy techniques are employed to determine the particle sizes and morphologies (every particle is formed by a number of crystallites). In many cases there is no direct correlation between crystallite size (determined from XRD) and particle size (determined from TEM).

The obtained spinel ferrites were easily separated from aqueous solution by means of a permanent magnet. For instance, the magnetic separation of $\mathrm{CoFe}_{2} \mathrm{O}_{4}$ spinel ferrite from the aqueous solution is shown in Figure 3(d) (before separation) and Figure 3(e) (after magnetic separation).

3.2. Adsorption Screening Test. The objective of the screening test was to compare the performances of the ferrites for adsorption of Congo-Red (CR) dye from aqueous solutions under certain conditions. The results of the screening test are shown in Figure 4. The highest adsorption performances (in terms of both color removal efficiency and adsorption capacity) were attributed to the adsorbent $\mathrm{NiFe}_{2} \mathrm{O}_{4}$ followed by $\mathrm{CoFe}_{2} \mathrm{O}_{4}$. The spinel ferrite $\mathrm{ZnFe}_{2} \mathrm{O}_{4}$ disclosed the lowest sorption performances (Figure 4). The higher adsorption capacities were correlated with the smaller particle size of ferrites determined from TEM analysis. Therefore, the spinel ferrites $\mathrm{NiFe}_{2} \mathrm{O}_{4}$ and $\mathrm{CoFe}_{2} \mathrm{O}_{4}$ with better sorption performances were used for the kinetics and isotherms studies.

3.3. Adsorption Kinetics. The adsorptions of CR onto $\mathrm{NiFe}_{2} \mathrm{O}_{4}$ and $\mathrm{CoFe}_{2} \mathrm{O}_{4}$ ferrites were studied versus time at $293 \mathrm{~K}$. Figure 5 shows the amount of the dye adsorbed $q_{t}(\mathrm{mg} / \mathrm{g})$ against the contact time $t$ ( $\mathrm{min}$ ) for two sorbent materials, that is, $\mathrm{CoFe}_{2} \mathrm{O}_{4}$ (Figure 5(a)) and $\mathrm{NiFe}_{2} \mathrm{O}_{4}$ (Figure 5(b)).

Several kinetic models have been employed in this study to fit the adsorption kinetics data, namely: (1) pseudofirst order (PFO) kinetics [16, 17], (2) pseudosecond order (PSO) kinetics [18], (3) pseudo-n-order (PnO) kinetics [19, 20], (4) mixed 1,2-order (MOE) kinetics [21, 22], and (5) intraparticle diffusion (ID) kinetics [23, 24]. The equations of kinetic models are summarized in Table 2 . The predictions given by kinetic models have been plotted as solid, dashed and dot lines in Figure 5.

To determine the goodness-of-fit between models' predictions and experimental data the average relative error (ARE) function has been calculated [25]:

$$
\mathrm{ARE}=\frac{100}{N} \sum_{j=1}^{N} \frac{\left|q_{j}^{\text {calc }}-q_{j}^{\text {exper }}\right|}{q_{j}^{\text {exper }}},
$$

where $q^{\text {exper }}$ denotes the experimental adsorption capacity $(\mathrm{mg} / \mathrm{g}), q^{\text {calc }}$ is the calculated adsorption capacity $(\mathrm{mg} / \mathrm{g}), \mathrm{N}$ is the number of data within the experimental curve, and $j$ is the integer index.

The parameters of kinetic models have been determined by Gauss-Newton nonlinear regression method using nlinfit matlab solver, and their values are reported in Table 3 . The average relative error (ARE) function are also summarized in Table 3.

As one can see from Figure 5, the best-fitting kinetic data is given by $\mathrm{PnO}$ model with $\mathrm{ARE}<0.75$ (Table 3 ). This suggests that the orders of the rate equations $(\mathrm{PnO})$ are of $n=$ 2.556 (for $\mathrm{CoFe}_{2} \mathrm{O}_{4}$ ) and $n=1.654$ (for $\mathrm{NiFe}_{2} \mathrm{O}_{4}$ ). Likewise, the PSO and MOE models approximate quite well the kinetic data with an average relative error less than $1 \%(\mathrm{ARE}<1)$. The kinetic model (PFO) fits satisfactorily the observations with the average relative errors of $4.3 \%$ and $2.6 \%$, for $\mathrm{CoFe}_{2} \mathrm{O}_{4}$ and $\mathrm{NiFe}_{2} \mathrm{O}_{4}$, respectively. The intraparticle diffusion (ID) model shows some discrepancy between the predicted data 

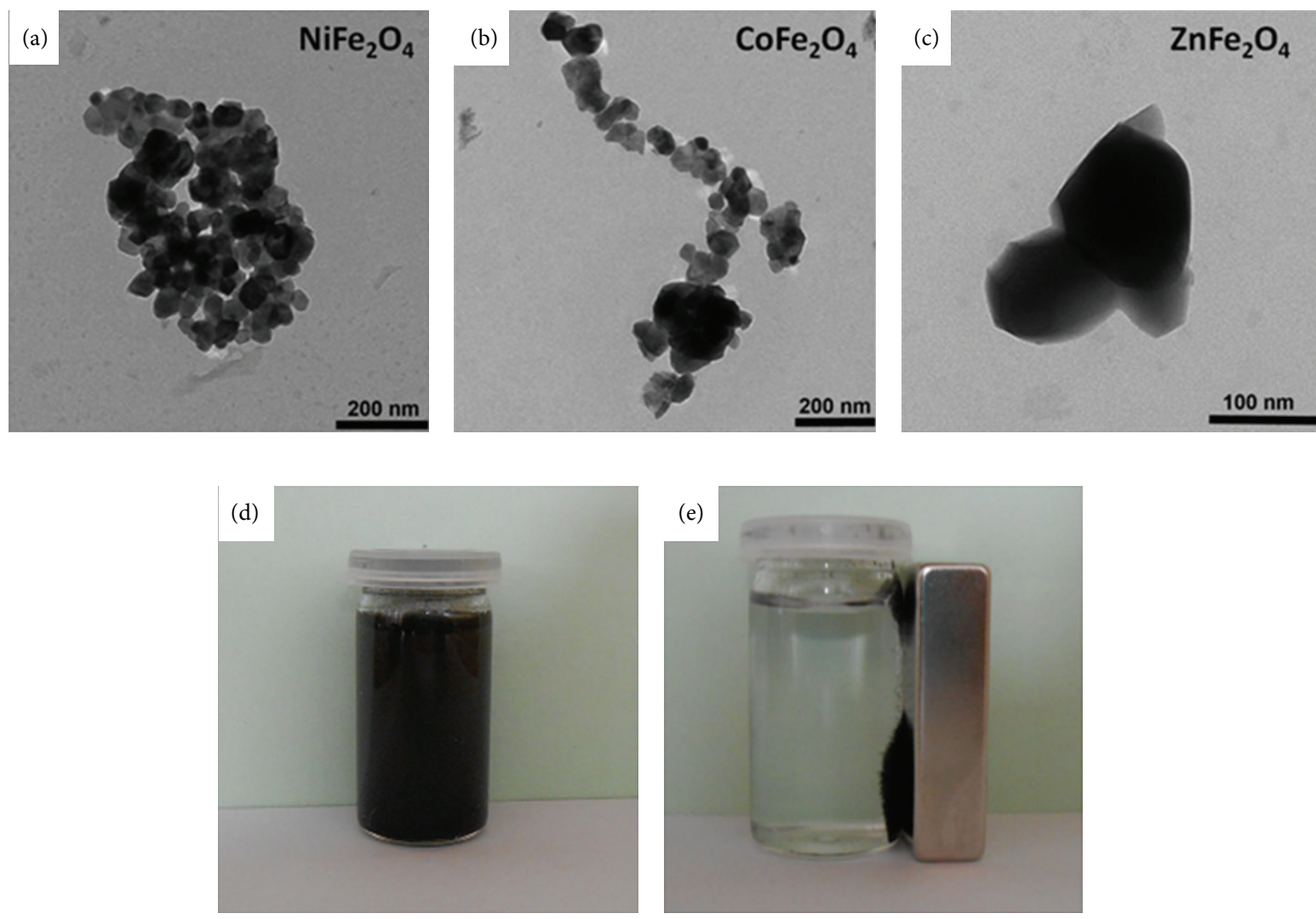

Figure 3: TEM micrographs of $\mathrm{MFe}_{2} \mathrm{O}_{4}\left(\mathrm{M}=\mathrm{Ni}\right.$, Co, and $\mathrm{Zn}$ ) spinel ferrites (a, b, and c) and images (d, e) of magnetic separation of CoFe $\mathrm{O}_{4}$ spinel ferrite from the aqueous solution with a permanent magnet: (d) before separation and (e) after magnetic separation.

TABLE 2: Kinetic models and the parameters for the adsorption kinetics.

\begin{tabular}{lccc}
\hline Abbreviation & $\begin{array}{c}\text { Kinetic model (rate } \\
\text { equation) }\end{array}$ & Kinetic model (nonlinear equation) & Parameters \\
\hline PFO & $\frac{d q_{t}}{d t}=k_{1}\left(q_{e}-q_{t}\right)$ & $q_{t}=q_{e}\left(1-e^{-k_{1} t}\right)$ & $q_{e}, k_{1}$ \\
\hline PSO & $\frac{d q_{t}}{d t}=k_{2}\left(q_{e}-q_{t}\right)^{2}$ & $q_{t}=\frac{k_{2} q_{e}^{2} t}{1+k_{2} q_{e} t}$ & $q_{e}, k_{2}$ \\
\hline PnO & $\frac{d q_{t}}{d t}=k_{n}\left(q_{e}-q_{t}\right)^{n}$ & $q_{t}=q_{e}-\left[(n-1) k_{n} t+q_{e}^{(1-n)}\right]^{1 /(1-n)}$ & $q_{e}, k_{n}$, and $n$ \\
\hline MOE & $\frac{d q_{t}}{d t}=\sum_{i} K_{i}\left(q_{e}-q_{t}\right)^{i}$ & $q_{t}=q_{e} \frac{1-e^{\left(-K_{1} t\right)}}{1-\left(K_{2} q_{e} /\left(K_{1}+K_{2} q_{e}\right)\right) e^{\left(-K_{1} t\right)}}$ & $q_{e}, K_{1}$, and $K_{2}$ \\
\hline ID & $\frac{d q_{t}}{d t}=\frac{k_{d}}{2 \sqrt{t}}$ & $q_{t}=k_{d} \sqrt{t}+J$ & $k_{d}, J$ \\
\hline
\end{tabular}

and experimental observations with the errors of $10-11 \%$. The kinetic data (Figure 5) suggest that $\mathrm{NiFe}_{2} \mathrm{O}_{4}$ ferrite is superior to $\mathrm{CoFe}_{2} \mathrm{O}_{4}$ for $\mathrm{CR}$ adsorption owing to higher values of adsorption capacity observed against the time.

3.4. Adsorption Isotherms. The adsorption of $\mathrm{CR}$ onto $\mathrm{NiFe}_{2} \mathrm{O}_{4}$ and $\mathrm{CoFe}_{2} \mathrm{O}_{4}$ has been studied against equilibrium concentration at different temperatures. From kinetic studies, the contact time has been fixed at $t=180 \mathrm{~min}$ to attain the stationary adsorption (equilibrium). Figure 6 shows the amount of dye adsorbed at equilibrium $q_{e}(\mathrm{mg} / \mathrm{g})$ versus the equilibrium concentration $C_{e}(\mathrm{mg} / \mathrm{L})$ for both sorbent materials $\mathrm{CoFe}_{2} \mathrm{O}_{4}$ (Figure 6(a)) and $\mathrm{NiFe}_{2} \mathrm{O}_{4}$ (Figure 6(b)).
As one can see, the adsorption of CR goes up with increment of equilibrium concentration for both cases $\left(\mathrm{CoFe}_{2} \mathrm{O}_{4}\right.$ and $\mathrm{NiFe}_{2} \mathrm{O}_{4}$ ).

The equilibrium data were analyzed using the isotherm models of Freundlich and Langmuir. Freundlich model is an empirical adsorption isotherm for nonideal adsorption on heterogeneous surfaces and multisite adsorption process, which may be expressed by the following equation [26, 27]:

$$
q_{e}=K_{F} C_{e}^{1 / n_{F}},
$$

where $C_{e}(\mathrm{mg} / \mathrm{L})$ is the dye concentration in the liquid at equilibrium, $q_{e}(\mathrm{mg} / \mathrm{g})$ is the amount of dye adsorbed at 


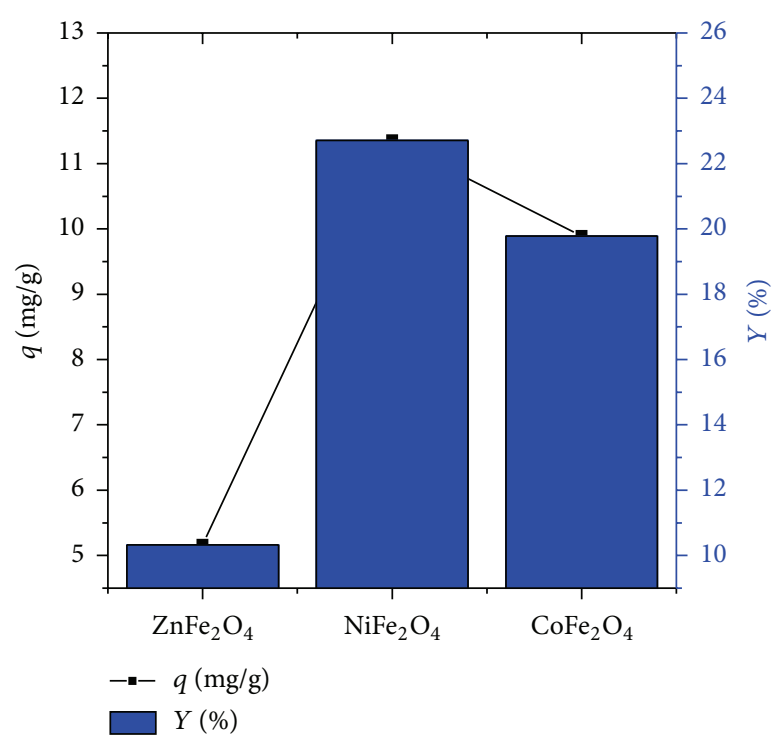

FIGURE 4: Screening test for CR dye adsorption using different ferrite adsorbents showing the adsorption capacity and color removal efficiency determined under the following conditions: $C_{0}=50 \mathrm{mg} / \mathrm{L}$, $\mathrm{SD}=1 \mathrm{~g} / \mathrm{L}, t=180 \mathrm{~min}$, and $T=293 \mathrm{~K}$.

TABLE 3: Kinetic parameters for Congo-Red adsorption onto spinel ferrites, determined by the nonlinear regression method.

\begin{tabular}{|c|c|c|}
\hline $\begin{array}{l}\text { Kinetic model and } \\
\text { parameters }\end{array}$ & Adsorbent: $\mathrm{CoFe}_{2} \mathrm{O}_{4}$ & Adsorbent: $\mathrm{NiFe}_{2} \mathrm{O}_{4}$ \\
\hline \multirow{3}{*}{$\mathrm{PFO}$} & $q_{e}=9.6461(\mathrm{mg} / \mathrm{g})$ & $q_{e}=11.1255(\mathrm{mg} / \mathrm{g})$ \\
\hline & $k_{1}=0.0527$ & $k_{1}=0.0623$ \\
\hline & $\mathrm{ARE}=4.307$ & $\mathrm{ARE}=2.605$ \\
\hline \multirow{3}{*}{ PSO } & $q_{e}=10.5168(\mathrm{mg} / \mathrm{g})$ & $q_{e}=11.9730(\mathrm{mg} / \mathrm{g})$ \\
\hline & $k_{2}=0.0080$ & $k_{2}=0.0089$ \\
\hline & $\mathrm{ARE}=0.916$ & $\mathrm{ARE}=0.941$ \\
\hline \multirow{4}{*}{$\mathrm{PnO}$} & $q_{e}=11.198(\mathrm{mg} / \mathrm{g})$ & $q_{e}=11.603(\mathrm{mg} / \mathrm{g})$ \\
\hline & $k_{n}=2.2909 \times 10^{-3}$ & $k_{n}=1.8229 \times 10^{-2}$ \\
\hline & $n=2.5561$ & $n=1.6539$ \\
\hline & $\mathrm{ARE}=0.503$ & $\mathrm{ARE}=0.745$ \\
\hline \multirow{4}{*}{$\mathrm{MOE}$} & $q_{e}=10.517(\mathrm{mg} / \mathrm{g})$ & $q_{e}=11.4637(\mathrm{mg} / \mathrm{g})$ \\
\hline & $K_{1}=3.3965 \times 10^{-6}$ & $K_{1}=0.0153$ \\
\hline & $K_{2}=7.9652 \times 10^{-3}$ & $K_{2}=0.0076$ \\
\hline & $\mathrm{ARE}=0.938$ & $\mathrm{ARE}=0.893$ \\
\hline \multirow{3}{*}{ ID } & $k_{d}=0.5369$ & $k_{d}=0.5879$ \\
\hline & $J=3.2066$ & $J=4.1416$ \\
\hline & $\mathrm{ARE}=10.624$ & $\mathrm{ARE}=11.443$ \\
\hline
\end{tabular}

equilibrium, $K_{F}\left[(\mathrm{mg} / \mathrm{g})(\mathrm{L} / \mathrm{g})^{1 / n_{F}}\right]$ is the Freundlich constant, and $n_{F}$ is the parameter which describes the system heterogeneity.
The basic assumption of the Langmuir theory is that adsorption takes place at specific homogeneous sites within the sorbent $[28,29]$ :

$$
q_{e}=\frac{q_{m} K_{L} C_{e}}{1+K_{L} C_{e}},
$$

where $q_{m}(\mathrm{mg} / \mathrm{g})$ is the amount of the solute adsorbed for a complete monolayer and $K_{L}(\mathrm{~L} / \mathrm{mg})$ is the Langmuir isotherm constant.

The parameters of Freundlich and Langmuir models have been calculated by means of Gauss-Newton nonlinear regression method. To estimate the goodness-of-fit for isotherms, the average relative errors (ARE) have been computed according to (3). The parameters of isotherm models as well as the values of the average relative errors are summarized in Table 4. The results reveal that Freundlich model is more suitable than Langmuir model to fit the adsorption data. This indicates the heterogeneous adsorption of CR onto magnetic sorbents $\mathrm{CoFe}_{2} \mathrm{O}_{4}$ and $\mathrm{NiFe}_{2} \mathrm{O}_{4}$.

Figure 6 disclosed that the adsorption of CR onto ferrites decreased with increment of temperature. This effect is more pronounced for $\mathrm{CoFe}_{2} \mathrm{O}_{4}$ and less significant for $\mathrm{NiFe}_{2} \mathrm{O}_{4}$ sorbent (Figure 6). Similar trends for ferrite-dye systems were also reported by other authors $[7,8]$.

In addition, the equilibrium adsorption data have been modeled using the Dubinin-Radushkevich (D-R) isotherm. The D-R model has been employed to distinguish between physical and chemical adsorption. The $\mathrm{D}-\mathrm{R}$ isotherm parameters are reported in Table 4 . Based on $\mathrm{D}-\mathrm{R}$ isotherm analysis, the mean free energy of adsorption, $E_{S}\left(\mathrm{~kJ} \mathrm{~mol}^{-1}\right)$, has been calculated [30, 31]. In our case, the values of mean free energy $E_{S}$ were higher than $8\left(\mathrm{~kJ} \mathrm{~mol}^{-1}\right)$ (Table 4$)$ suggesting that the uptake of CR onto ferrite materials was based on chemical adsorption.

3.5. Thermodynamic Parameters. The thermodynamic parameters for CR adsorption onto spinel ferrites have been calculated according to the methodology presented elsewhere [23]. The thermodynamic parameters for CR adsorption onto $\mathrm{CoFe}_{2} \mathrm{O}_{4}$ sorbent were found to be $\Delta G=$ $-30.861 \pm 2.794 \mathrm{~kJ} / \mathrm{mol}, \Delta H=12.828 \mathrm{~kJ} / \mathrm{mol}$, and $\Delta S=$ $139.579 \pm 0.112 \mathrm{~J} / \mathrm{mol} \mathrm{K}$. For CR adsorption onto $\mathrm{NiFe}_{2} \mathrm{O}_{4}$ sorbent, the values of the thermodynamic parameters were $\Delta G=-31.875 \pm 3.040 \mathrm{~kJ} / \mathrm{mol}, \Delta H=15.301 \mathrm{~kJ} / \mathrm{mol}$, and $\Delta S=150.725 \pm 2.142 \mathrm{~J} / \mathrm{mol} \mathrm{K}$. The negative values of free energy $\Delta G$ revealed the spontaneous nature of the adsorption process. The positive enthalpy indicated the endothermic effect of the adsorption. The positive values of entropy $\Delta S$ disclosed the increasing of randomness at the solid/liquid interface, suggesting the affinity of CR molecules on the surface of ferrite adsorbents.

3.6. Response Surface Modeling of the Adsorption Process. Due to its highest sorption performances, the material $\mathrm{NiFe}_{2} \mathrm{O}_{4}$ was selected for modeling and optimization of the adsorption process. To this end, the response surface methodology (RSM) [32-34] was employed to build the multiple regression models, which are the mathematical relationships between 


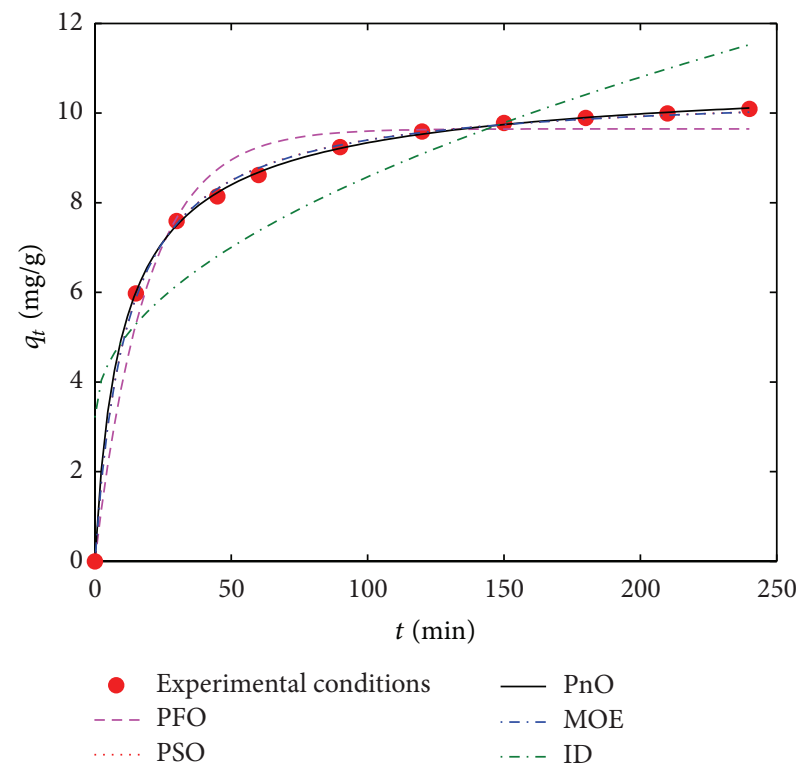

(a)

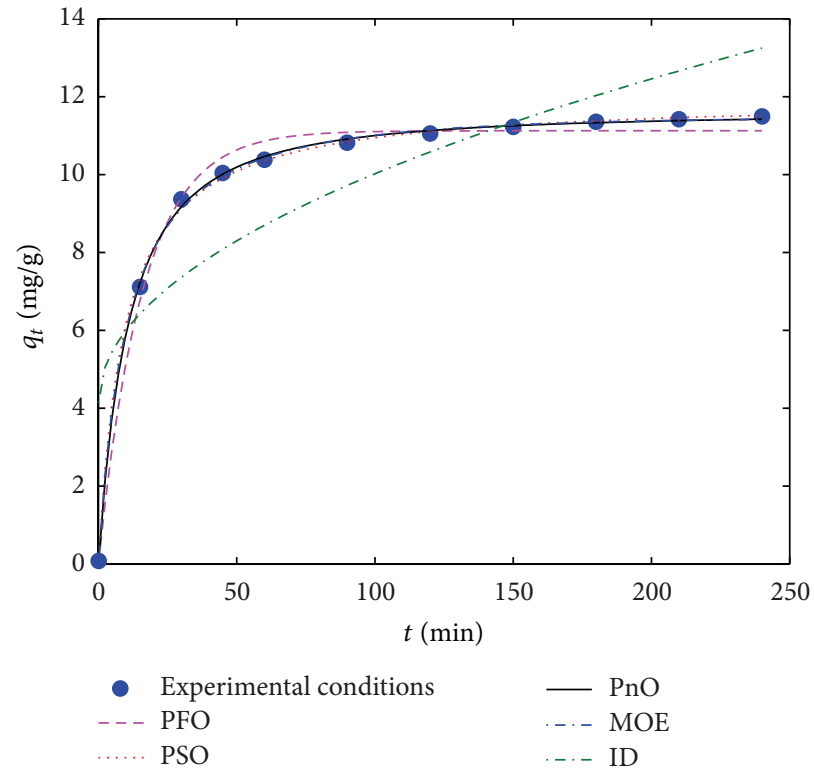

(b)

Figure 5: Adsorption kinetics data for Congo-Red removal by ferrite sorbents and comparison of kinetic models: (a) adsorbent CoFe $\mathrm{O}_{4}$ and (b) adsorbent $\mathrm{NiFe}_{2} \mathrm{O}_{4}$; experimental conditions: $C_{0}=50 \mathrm{mg} / \mathrm{L}, \mathrm{SD}=1 \mathrm{~g} / \mathrm{L}$ and $T=293 \mathrm{~K}$.

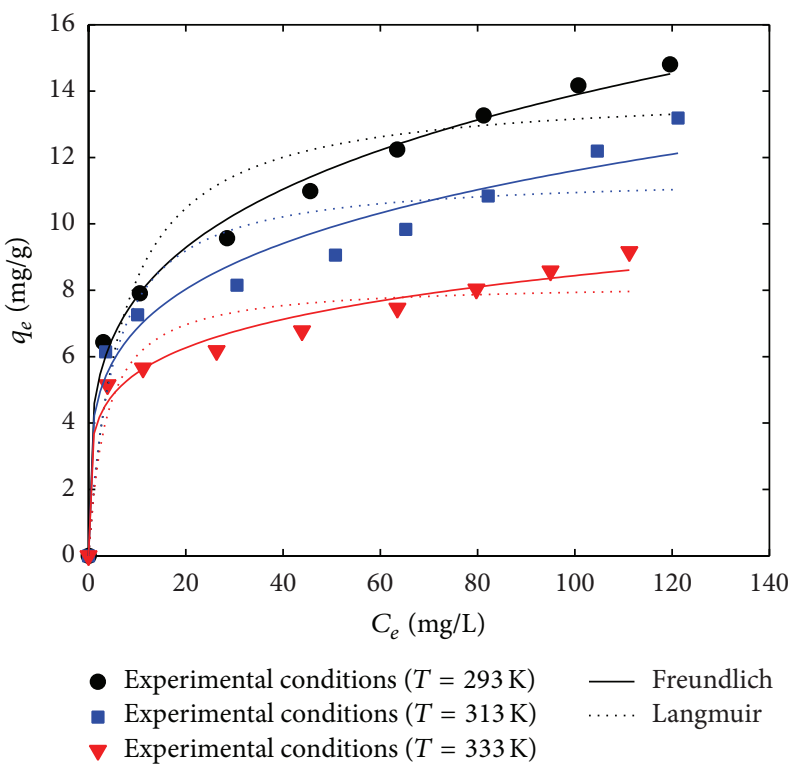

(a)

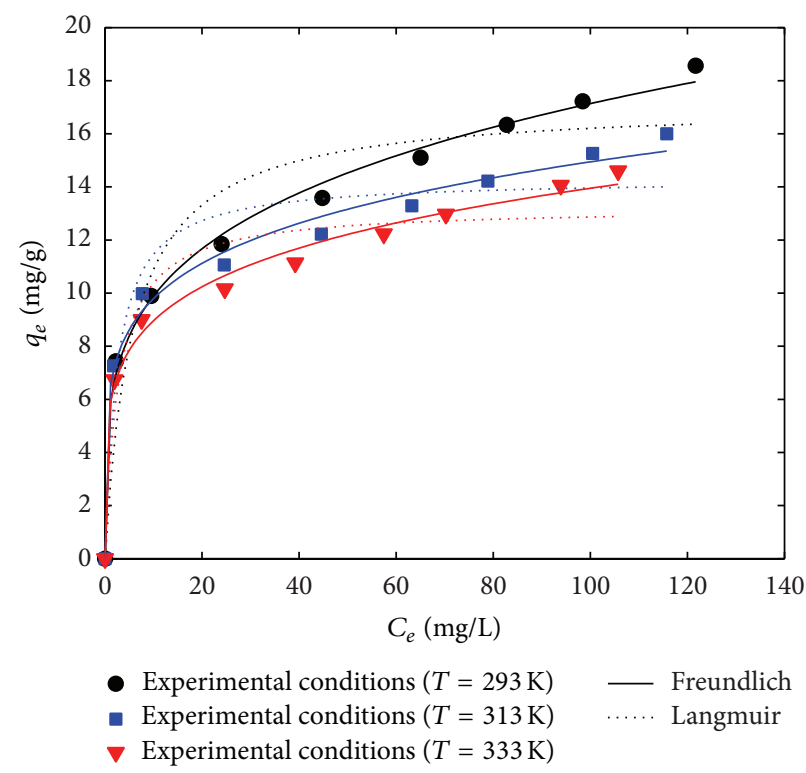

(b)

Figure 6: Adsorption isotherms for Congo-Red removal by ferrite sorbents fitted by the Freundlich (solid lines) and Langmuir (dot lines) models: (a) adsorbent $\mathrm{CoFe}_{2} \mathrm{O}_{4}$ and (b) adsorbent $\mathrm{NiFe}_{2} \mathrm{O}_{4}$; experimental conditions: $\mathrm{SD}=1 \mathrm{~g} / \mathrm{L}$ and $t=180 \mathrm{~min}$.

responses (outputs) and regressor variables (input factors) of the process under investigation.

The controllable factors (regressors) employed for the experimental design of the adsorption process were the contact time $t(\mathrm{~min})$, initial dye concentration $C_{0}(\mathrm{mg} / \mathrm{L})$, and the sorbent dosage $\mathrm{SD}(\mathrm{g} / \mathrm{L})$. For modeling purpose, the values of these factors were converted into dimensionless values, known as coded levels. The relation between actual values of factors and their coded levels is summarized in Table 5.

For the investigation of the adsorption process, the central composite design (CCD) of orthogonal type was employed (Table 6). Two responses were determined experimentally for each run, that is, color removal efficiency $Y(\%)$ and adsorption capacity $q(\mathrm{mg} / \mathrm{g})$. The values of these responses are reported in Table 6 . Note that all the 
TABLE 4: Isotherm parameters for Congo-Red adsorption onto spinel ferrites.

\begin{tabular}{lcccc}
\hline \multirow{2}{*}{ Isotherm } & \multicolumn{2}{c}{ Adsorbent: $\mathrm{CoFe}_{2} \mathrm{O}_{4}$} & \multicolumn{2}{c}{${\text { Adsorbent: } \mathrm{NiFe}_{2} \mathrm{O}_{4}}$} \\
& $T=293 \mathrm{~K}$ & $T=333 \mathrm{~K}$ & $\mathrm{~T}=293 \mathrm{~K}$ & $K_{F}=5.7563$ \\
\hline Freundlich & $K_{F}=4.3932$ & $K_{F}=3.5983$ & $K_{F}=5.7119$ & $n_{F}=5.2030$ \\
$K_{F}(\mathrm{mg} / \mathrm{g})(\mathrm{L} / \mathrm{g})^{1 / n_{F}}$ & $n_{F}=4.0025$ & $n_{F}=5.4013$ & $n_{F}=4.1917$ & $\mathrm{ARE}=3.30$ \\
$n_{F}$ & $\mathrm{ARE}=3.21$ & $\mathrm{ARE}=4.71$ & $K_{L}=0.1746$ & $K_{L}=0.3643$ \\
Langmuir & $K_{L}=0.1460$ & $K_{L}=0.2751$ & $q_{m}=17.133$ & $q_{m}=13.218$ \\
$K_{L}(\mathrm{~L} / \mathrm{mg})$ & $q_{m}=14.059$ & $q_{m}=8.224$ & $\mathrm{ARE}=12.10$ & $\mathrm{ARE}=9.97$ \\
$q_{m}(\mathrm{mg} / \mathrm{g})$ & $\mathrm{ARE}=11.72$ & $\mathrm{ARE}=10.43$ & $q_{d}=0.0380$ & $q_{d}=0.0265$ \\
$\mathrm{D}-\mathrm{R}$ & $q_{d}=0.0319$ & $q_{d}=0.0153$ & $K_{D}=0.0020$ & $K_{D}=0.0011$ \\
$q_{d}(\mathrm{~g} / \mathrm{g})$ & $K_{D}=0.0021$ & $K_{D}=0.0010$ & $E_{S}=15.669$ & $E_{S}=21.225$ \\
$K_{D}\left(\mathrm{~mol}^{2} \mathrm{~kJ}^{-2}\right)$ & $E_{S}=15.335$ & $E_{S}=21.936$ & $\mathrm{ARE}=4.05$ & $\mathrm{ARE}=3.69$ \\
$E_{S}\left(\mathrm{~kJ} \mathrm{~mol}{ }^{-1}\right)$ & $\mathrm{ARE}=4.78$ & $\mathrm{ARE}=5.51$ &
\end{tabular}

TABLE 5: Input variables and their coded and actual values used for adsorption experiments.

\begin{tabular}{|c|c|c|c|c|c|c|}
\hline \multirow{2}{*}{ Input variables (factors) } & \multirow{2}{*}{ Coded variables } & \multicolumn{5}{|c|}{ Coded levels versus actual values } \\
\hline & & $-\alpha$ & -1 & 0 & +1 & $+\alpha$ \\
\hline Contact time, $t(\min )$ & $x_{1}$ & 14 & 30 & 105 & 180 & 196 \\
\hline Initial dye concentration, $C_{0}(\mathrm{mg} / \mathrm{L})$ & $x_{2}$ & 13.6 & 20.0 & 50.0 & 80.0 & 86.5 \\
\hline Sorbent dosage $\left(\mathrm{NiFe}_{2} \mathrm{O}_{4}\right), \mathrm{SD}(\mathrm{g} / \mathrm{L})$ & $x_{3}$ & 0.57 & 1.00 & 3.00 & 5.00 & 5.43 \\
\hline
\end{tabular}

Note: $\alpha=1.215$ (value of axial point for orthogonal CCD in case of three factors).

experiments were carried out at room temperature $(293 \mathrm{~K})$ and naturally occurring $\mathrm{pH}$ 6.80. Based on the experimental design data (Table 6), two statistical models were constructed using the multiple regression method [32-34]. The developed fitted models can be presented for coded variables $\left(x_{1}, x_{2}\right.$, and $x_{3}$ ) as follows:

$$
\begin{aligned}
\widehat{Y}= & 74.15+4.569 x_{1}-14.82 x_{2}+25.38 x_{3}-2.871 x_{1}^{2} \\
& -10.785 x_{3}^{2}+2.685 x_{2} x_{3}, \\
\widehat{q}= & 10.489+0.83 x_{1}+2.936 x_{2}-2.719 x_{3}-0.637 x_{1}^{2} \\
& -1.51 x_{2}^{2}+0.467 x_{3}^{2}-0.353 x_{1} x_{3}+0.511 x_{2} x_{3},
\end{aligned}
$$

subject to $x_{i} \in[-\alpha, \alpha]$, for all $i=\overline{1,3}$.

The significance of all regression coefficients in (6) was estimated using the Student $t$-test [32]. Thus, the fitted models (6) involve only the significant coefficients. Likewise, the models were validated statistically using the analysis of variance (ANOVA). The detailed description of this statistical method can be found elsewhere [33, 34]. The results of ANOVA are summarized in Table 7 . Since the $P$ values are less than 0.0001 both models are statistically significant. The fact that the values of the coefficients of determination $R^{2}$ are high (close to 1) indicates that the observed responses are quite close to those predicted.

The goodness-of-fits between predictions and experimental observations are illustrated in Figure 7. Both fitted models yield well-behaved predictions for the responses $Y$ (\%) and $q(\mathrm{mg} / \mathrm{g})$, since the data are scattered close to the bisector. Hence, the parity plot (Figure 7) is consistent with the ANOVA results (Table 7).
The multiple regression models with actual variables have been developed by the substitution technique and may be written as follows:

$$
\begin{aligned}
\widehat{Y}= & 31.205+0.168 t-0.628 C_{0}+26.63 \mathrm{SD}-5.103 \\
& \times 10^{-4} t^{2}-2.696 \mathrm{SD}^{2}+0.045 C_{0} \times \mathrm{SD}, \\
\widehat{q}= & 4.66+0.04 t+0.24 C_{0}-2.24 \mathrm{SD}-1.13 \times 10^{-4} t^{2} \\
& -1.68 \times 10^{-3} C_{0}^{2}+0.12 \mathrm{SD}^{2} \cdots-2.35 \times 10^{-3} t \\
& \times \mathrm{SD}+8.51 \times 10^{-3} C_{0} \times \mathrm{SD},
\end{aligned}
$$

subject to $14 \leq t \leq 196(\mathrm{~min}) ; 13.6 \leq C_{0} \leq 86.5(\mathrm{mg} / \mathrm{L}) ;$ $0.57 \leq \mathrm{SD} \leq 5.43(\mathrm{~g} / \mathrm{L})$.

The 3D plots of response surfaces showing the coupling effects of factors on responses are illustrated in Figures 8-9.

Figure 8(a) shows that the increment of sorbent dosage (SD) variable leads to the increasing of the color removal efficiency, $\hat{Y}(\%)$. By contrast, the greater the dye concentration $\left(C_{0}\right)$ is, the less the removal efficiency is. An interaction effect is observed between these factors, $C_{0}$ and SD. Thus, the effect of the initial dye concentration is more significant at low levels of the sorbent dosage SD. The influence of SD variable is stronger at higher values of $C_{0}$. According to Figure 8(b), the increment of $\mathrm{CR}$ concentration $\left(C_{0}\right)$ improves the values of the adsorption capacity, $\hat{q}(\mathrm{mg} / \mathrm{g})$. The increasing of the sorbent dosage (SD) diminishes the adsorption capacity $(\widehat{q})$. Due to the factors' interaction, the effect of sorbent dosage is more pronounced at lower values of initial dye concentration.

As one can see from Figure 9(a), the increasing of both contact time and sorbent dosage leads to higher values of color removal efficiency, $\widehat{Y}(\%)$. The effect of the sorbent 
TABLE 6: Central composite design (CCD) of orthogonal type used for adsorption experiments (CR onto $\mathrm{NiFe}_{2} \mathrm{O}_{4}$ ).

\begin{tabular}{|c|c|c|c|c|c|c|c|c|}
\hline \multirow{3}{*}{ Run } & \multicolumn{6}{|c|}{ Factors (controllable input variables) } & \multicolumn{2}{|c|}{ Responses (experimental values) } \\
\hline & \multicolumn{2}{|c|}{$t,(\min )$} & \multicolumn{2}{|c|}{$C_{0},(\mathrm{mg} / \mathrm{L})$} & \multicolumn{2}{|c|}{$\mathrm{SD},(\mathrm{g} / \mathrm{L})$} & \multirow[b]{2}{*}{$Y,(\%)$} & \multirow[b]{2}{*}{$q,(\mathrm{mg} / \mathrm{g})$} \\
\hline & $x_{1}$ & $t$ & $x_{2}$ & $C_{0}$ & $x_{3}$ & $\mathrm{SD}$ & & \\
\hline 1 & +1 & 180 & +1 & 80.0 & +1 & 5.00 & 79.057 & 10.209 \\
\hline 2 & -1 & 30 & +1 & 80.0 & +1 & 5.00 & 67.367 & 8.628 \\
\hline 3 & +1 & 180 & -1 & 20.0 & +1 & 5.00 & 97.143 & 3.184 \\
\hline 4 & -1 & 30 & -1 & 20.0 & +1 & 5.00 & 95.035 & 3.138 \\
\hline 5 & +1 & 180 & +1 & 80.0 & -1 & 1.00 & 22.026 & 14.634 \\
\hline 6 & -1 & 30 & +1 & 80.0 & -1 & 1.00 & 18.094 & 12.117 \\
\hline 7 & +1 & 180 & -1 & 20.0 & -1 & 1.00 & 59.247 & 10.127 \\
\hline 8 & -1 & 30 & -1 & 20.0 & -1 & 1.00 & 48.110 & 8.195 \\
\hline 9 & $+\alpha$ & 196 & 0 & 50.0 & 0 & 3.00 & 77.902 & 10.868 \\
\hline 10 & $-\alpha$ & 14 & 0 & 50.0 & 0 & 3.00 & 60.478 & 8.390 \\
\hline 11 & 0 & 105 & $+\alpha$ & 86.5 & 0 & 3.00 & 54.426 & 12.956 \\
\hline 12 & 0 & 105 & $-\alpha$ & 13.6 & 0 & 3.00 & 95.025 & 3.727 \\
\hline 13 & 0 & 105 & 0 & 50.0 & $+\alpha$ & 5.43 & 93.258 & 7.198 \\
\hline 14 & 0 & 105 & 0 & 50.0 & $-\alpha$ & 0.57 & 21.775 & 15.317 \\
\hline 15 & 0 & 105 & 0 & 50.0 & 0 & 3.00 & 73.747 & 10.244 \\
\hline 16 & 0 & 105 & 0 & 50.0 & 0 & 3.00 & 73.305 & 10.350 \\
\hline
\end{tabular}

TABLE 7: Analysis of variance (ANOVA) for the significance of the multiple regression models.

\begin{tabular}{|c|c|c|c|c|c|c|c|}
\hline Source & $\mathrm{DF}^{\mathrm{a}}$ & $\mathrm{SS}^{\mathrm{b}}$ & $\mathrm{MS}^{\mathrm{c}}$ & $F$-value & $P$ value & $R^{2}$ & $R_{\mathrm{adj}}^{2}$ \\
\hline \multicolumn{8}{|c|}{$Y$-response (color removal efficiency) } \\
\hline Model & 6 & $1.037 \times 10^{4}$ & $1.728 \times 10$ & & & & \\
\hline Residual & 9 & 147.912 & 16.435 & 105.139 & $<0.0001$ & 0.986 & 0.977 \\
\hline Total & 15 & $1.052 \times 10^{4}$ & & & & & \\
\hline \multicolumn{8}{|c|}{$q$-response (adsorption capacity) } \\
\hline Model & 8 & 199.745 & 24.968 & & & & \\
\hline Residual & 7 & 5.513 & 0.788 & 31.700 & $<0.0001$ & 0.973 & 0.942 \\
\hline Total & 15 & 205.259 & & & & & \\
\hline
\end{tabular}

dosage is more noticeable than the effect of the contact time. According to Figure 9(b), the increment of the contact time leads to a gradual increasing of the adsorption capacity, $\widehat{q}$ $(\mathrm{mg} / \mathrm{g})$. By contrast, as the sorbent dosage gets higher the adsorption capacity goes down. This may be related to the fact that the adsorbent material is not completely saturated with the solute at high sorbent dosages. The effect of the sorbent dosage is much more discerned than the effect of the contact time.

3.7. Optimization of the Adsorption Process. The main objective of the experimental design and response surface modeling is to optimize the investigated process. In this work, the model-based optimization of the adsorption process (CR onto $\mathrm{NiFe}_{2} \mathrm{O}_{4}$ ) has been approached via two strategies, that is, single-objective optimization (case 1) and multiobjective optimization (case 2).

3.7.1. Single-Objective Optimization (Case 1). In this case, the objective was to maximize only the color removal efficiency
$\widehat{Y}(\%)$ since this response was considered a priority from the environmental standpoint. The model-based optimization notation, for case 1 , is given by

$$
\begin{aligned}
\max & \widehat{Y}\left(x_{1}, x_{2}, x_{3}\right), \\
\text { subject to: } & x_{i} \in[-\alpha, \alpha], \quad \forall i=\overline{1,3} .
\end{aligned}
$$

In this study, the genetic algorithm (GA) was employed to solve the single-objective optimization problem given by (8). To this end, the optim_ga solver was used, implemented in SciLab 5.4.1 open-source software. The optimal solution in terms of actual values of factors is $t^{*}=165 \mathrm{~min}$, $C_{0}^{*}=13.6 \mathrm{mg} / \mathrm{L}$, and $\mathrm{SD}^{*}=5.05 \mathrm{~g} / \mathrm{L}$ (Table 8 ). Under such conditions, the predicted response is $\widehat{Y}=105.314$, and the observed response is $Y=98.995 \%$. This is the maximal value of the removal efficiency obtained in all the experiments done in this work. Note that under these conditions only the removal efficiency has been improved, while adsorption 


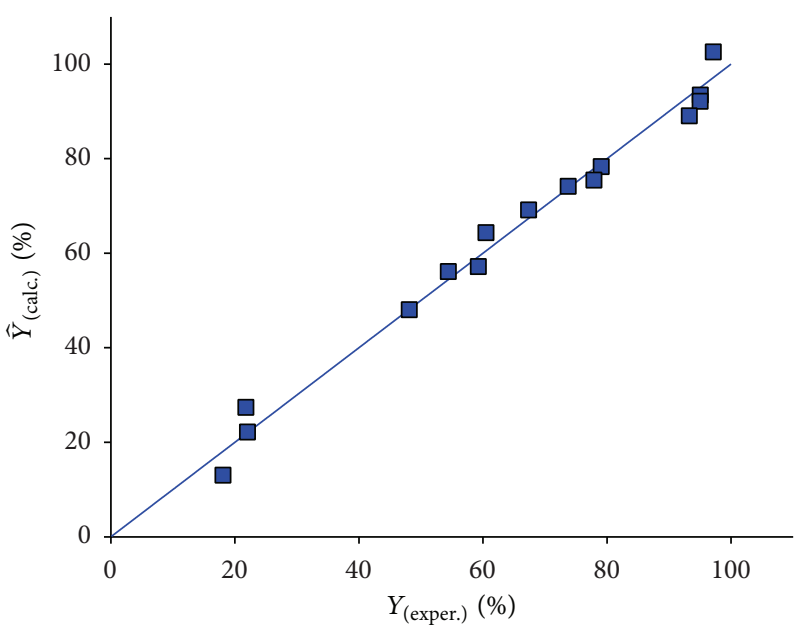

(a)

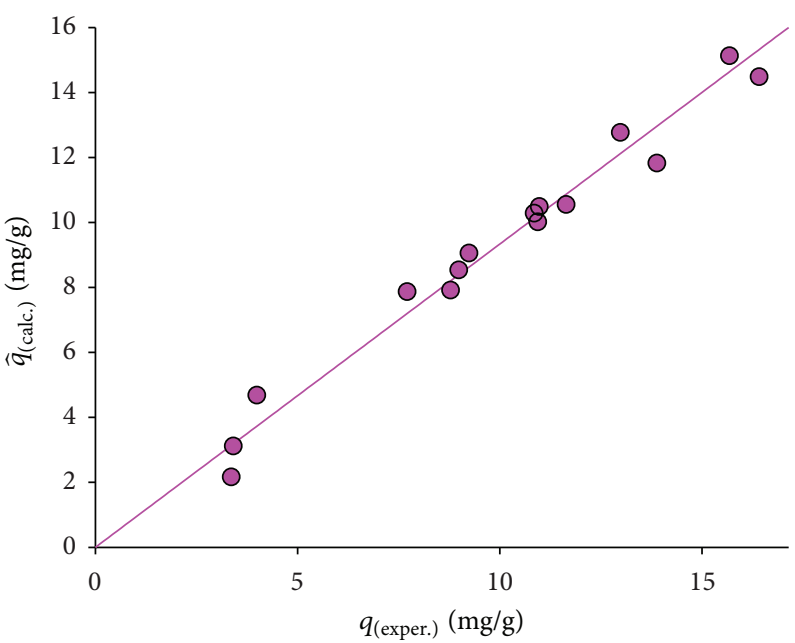

(b)

FIGURE 7: Parity plot showing the agreement between experimental and calculated responses: (a) color removal efficiency and (b) adsorption capacity.

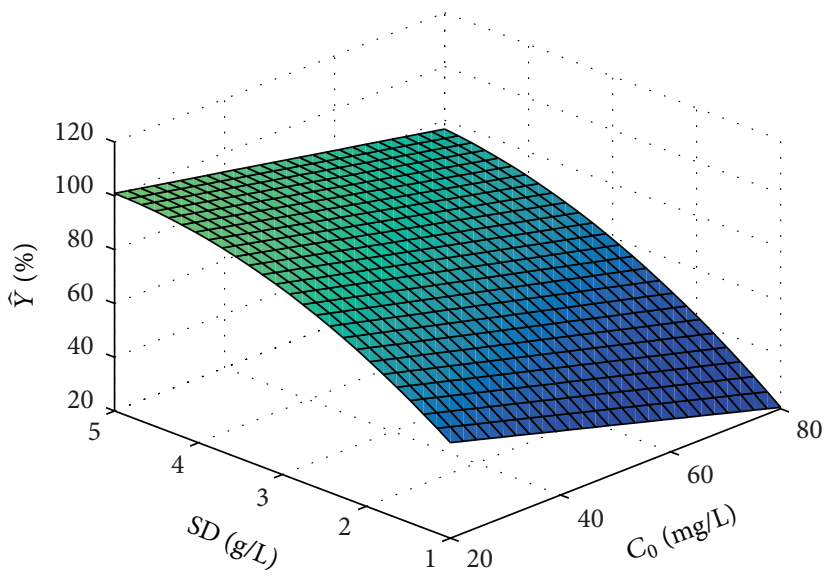

(a)

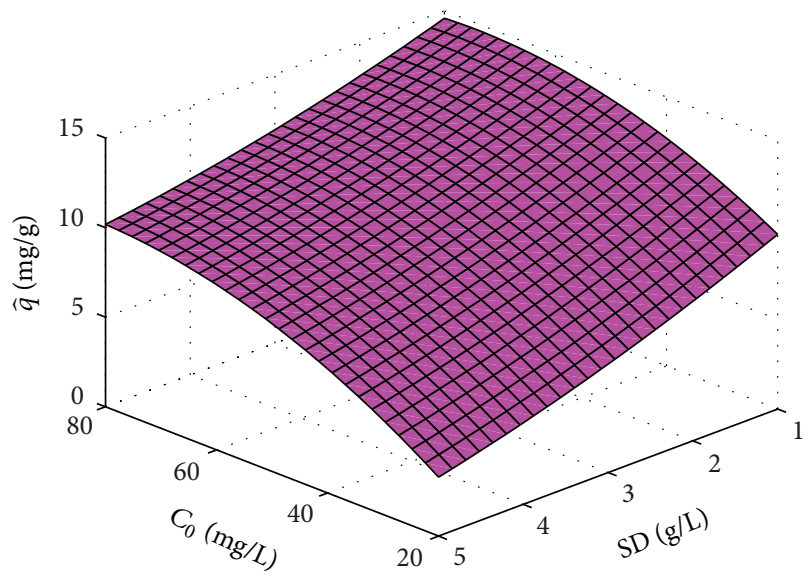

(b)

FIGURE 8: Response surface plot showing the coupling effects of SD and $C_{0}$ factors (at $t=105 \mathrm{~min}$ ) on (a) dye removal efficiency $\widehat{Y}$ (\%) and (b) adsorption capacity $\hat{q}(\mathrm{mg} / \mathrm{g})$.

TABLE 8: Experimental confirmation of optimal point determined by GA (Case 1: single-objective optimization).

\begin{tabular}{lcccccc}
\hline$t^{*}$, & $C_{0}^{*}$, & $\mathrm{SD}^{*}$, & $\widehat{Y}$ & $\hat{q}$ & $Y,(\%)$ \\
$(\mathrm{min})$ & $(\mathrm{mg} / \mathrm{L})$ & $(\mathrm{g} / \mathrm{L})$ & $\begin{array}{c}q,(\mathrm{mg} / \mathrm{g}) \\
\text { predicted }\end{array}$ & $\begin{array}{c}\text { predicted } \\
\text { observed } \\
\text { observed }\end{array}$ \\
\hline 165 & 13.6 & 5.05 & 105.314 & 1.728 & 98.995 & 2.284
\end{tabular}

Note. The optimal solution in terms of coded variables is $\mathbf{x}^{*}=$ $[0.7957 ;-1.2150 ; 1.0254]^{\mathrm{T}}$.

capacity remained at the relatively low value, that is, $\widehat{q}=1.728$ (predicted) and $q=2.284 \mathrm{mg} / \mathrm{g}$ (experimental) (Table 8 ).

3.7.2. Multiobjective Optimization (Case 2). For case 2, the objective was to maximize simultaneously both the color removal efficiency $\widehat{Y}(\%)$ and the adsorption capacity $\widehat{q}$ $(\mathrm{mg} / \mathrm{g})$. Firstly, the region of interest (i.e., desirability zone close to the optimum) has been identified by visual inspection of the contour overlap plot shown in Figure 10. Herein, the superposition of the two response functions is depicted, that is, $\widehat{Y}$ and $\hat{q}$ (predicted responses). According to Figure 10, the responses are conflicting; that is, the increment of one response leads to a decrease in the value of another objective. The desirability region (colored yellow zone in Figure 10) corresponds to high $\mathrm{SD}$ and low $C_{0}$, for the fixed contact time close to the superior level (i.e., $t=180 \mathrm{~min}$ ). The multicriteria optimization problem may be written using the vector optimization notation as follows:

$$
\begin{gathered}
\max [\widehat{Y}(\mathbf{x}), \widehat{q}(\mathbf{x})]^{\mathrm{T}}, \\
\mathbf{x}=\left[x_{1}, x_{2}, x_{3}\right]^{\mathrm{T}}, \quad x_{i} \in[-\alpha, \alpha], \quad \forall i=\overline{1,3} .
\end{gathered}
$$




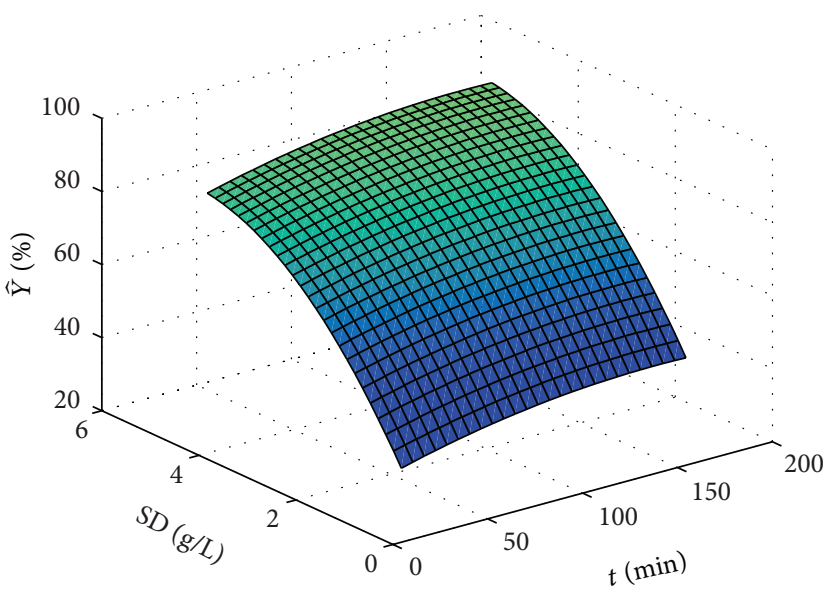

(a)

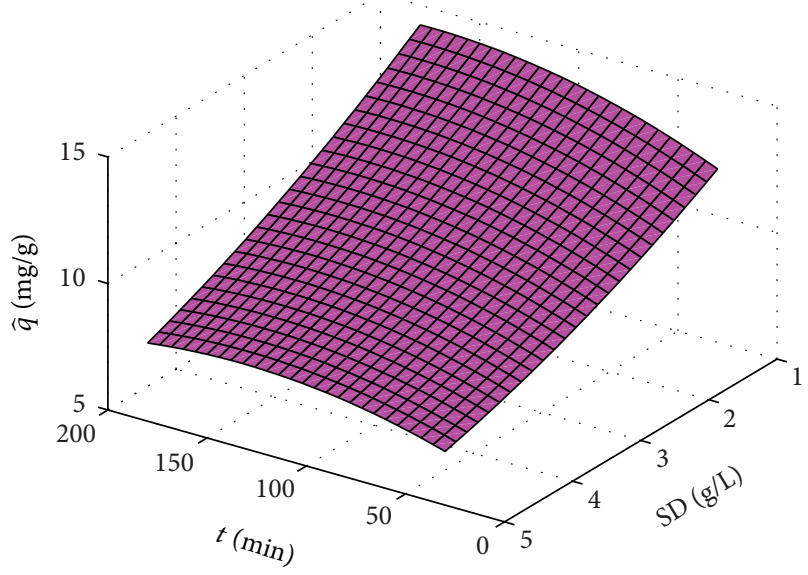

(b)

FIGURE 9: Response surface plot showing the coupling effects of $t$ and SD factors (at $C_{0}=50 \mathrm{mg} / \mathrm{L}$ ) on (a) dye removal efficiency $\widehat{Y}$ (\%) and (b) adsorption capacity $\hat{q}(\mathrm{mg} / \mathrm{g})$.

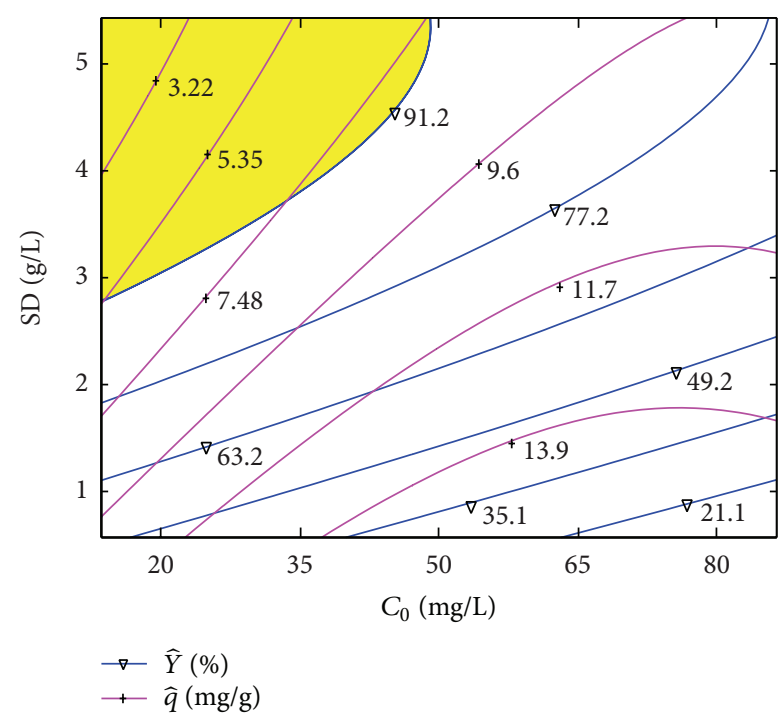

FIGURE 10: Overlap contour-lines plot of two response functions $\widehat{Y}$ and $\hat{q}$ depending on the values of factors $\mathrm{SD}(\mathrm{g} / \mathrm{L})$ and $C_{0}(\mathrm{mg} / \mathrm{L})$ for a constant level of $t=180(\mathrm{~min})$.

For solving the multiattribute optimization problem (9), one must find a set of solutions that satisfies both objectives. Such set of possible optimal solutions is known as nondominant solutions or Pareto population (optimality). A decisionmaker has to analyze the Pareto population and look for the best choice according to his priorities [35]. To solve the vector optimization problem (9), the nondominated sorting genetic algorithm-II (NSGA-II) [36] was employed using the solver optim_nsga2 included in SciLab-5.4.1 program. The results of optimization are shown in Figure 11.

The algorithm (NSGA-II) has randomly generated the initial population of 100 individual solutions inside of the valid region (Figure 11(a)). According to heuristic calculations, a set of the equivalent solutions (Pareto optimality) has been found as illustrated in Figure 11(b). The Pareto population involves many individual solutions (about 100), since the responses are conflicting and both objectives $(\widehat{Y}$ and $\hat{q}$ ) are treated with the same importance. To choose an optimal solution for experimental confirmation, the desirability function approach (DFA) has been employed additionally. In this respect, the individual solutions from Pareto optimality have been checked for the desirability by assigning different importance for responses. Thus, the response $\hat{Y}$ (color removal efficiency) has been considered more important than the response $\hat{q}$ (adsorption capacity) for the calculation of the desirability.

The desirability function approach deals with the calculation of individual desirability function $d_{k}$ for each considered response $y_{k}$ by converting the values of the response into the nondimensional scale ranging from 0 to 1 . For the maximization of a response $y_{k}$, the corresponding individual desirability function $d_{k}$ is of the-larger-the-best (LTB) type, and the conversion scheme can be written as [37]:

LTB-desirability:

$$
d_{k}= \begin{cases}0, & \text { if } y_{k} \leq y_{k}^{-}, \\ \left(\frac{y_{k}-y_{k}^{-}}{y_{k}^{+}-y_{k}^{-}}\right)^{W_{k}}, & \text { if } y_{k}^{-} \leq y_{k} \leq y_{k}^{+}, \\ 1, & \text { if } y_{k} \geq y_{k}^{+},\end{cases}
$$

where $y_{k}$ is the value of the response with index $k, y_{k}^{-}$is the lower-bound limit of the response, $y_{k}^{+}$is the upper-bound limit of the response, and $W_{k}$ is the weight coefficient indicating the importance of that response. The global desirability $D$ has been determined as the geometric mean of individual desirability functions $d_{k}[37,38]$ :

$$
D=\left(\prod_{k=1}^{z} d_{k}\right)^{1 / \sum_{k} W_{k}},
$$

where $z$ is the number of responses. The global desirability was calculated according to (11) for all individual solutions 


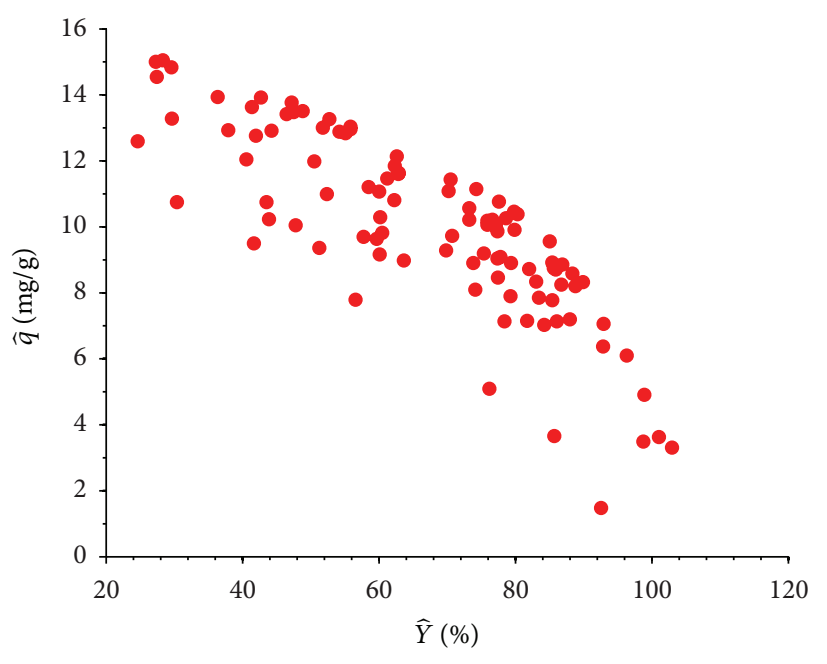

(a)

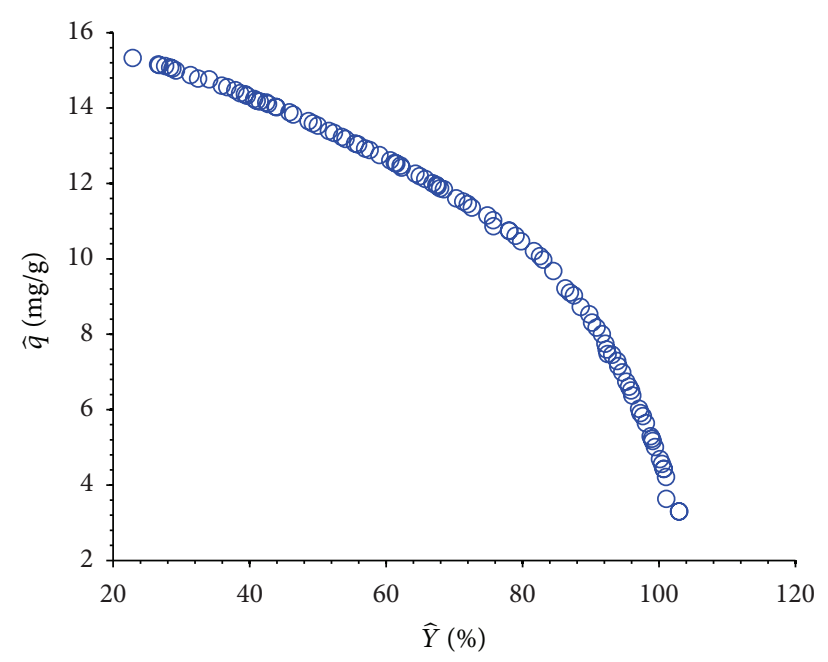

(b)

FIGURE 11: The results of NSGA-II optimization presented in the objective space: (a) initial population and (b) Pareto population.

TABLE 9: Experimental confirmation of optimal point determined by NSGA-II and DFA (Case 2: multiobjective optimization).

\begin{tabular}{lccccccc}
\hline$t^{*},(\min )$ & $C_{0}^{*},(\mathrm{mg} / \mathrm{L})$ & $\mathrm{SD}^{*},(\mathrm{~g} / \mathrm{L})$ & $\widehat{Y}$ predict. & $\widehat{q}$ predict. & $D$ desirability & $Y,(\%)$ exper. & $q,(\mathrm{mg} / \mathrm{g})$ exper. \\
\hline 152 & 39.0 & 4.59 & 93.894 & 7.290 & 0.7958 & 94.579 & 6.450
\end{tabular}

Note. The optimal solution in terms of coded variables is $\mathbf{x}^{*}=[0.6271 ;-0.3658 ; 0.7959]^{\mathrm{T}}$.

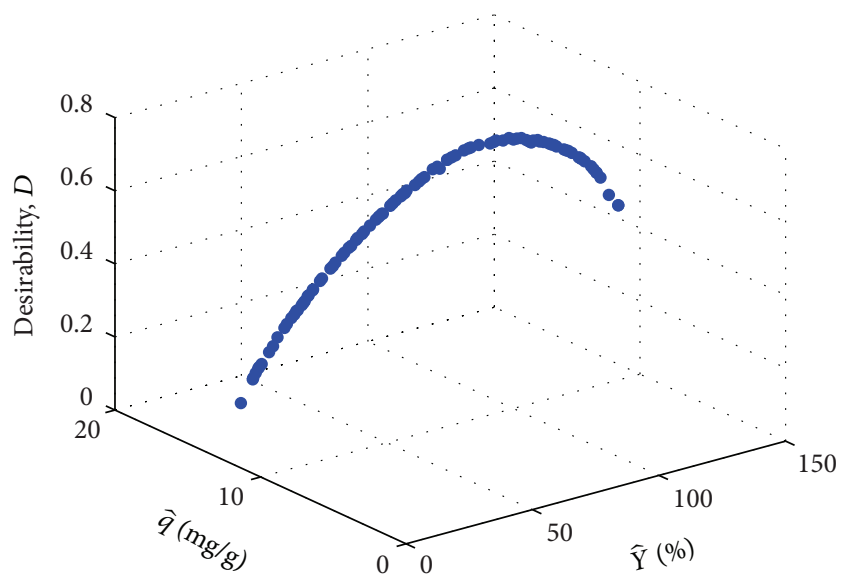

FIGURE 12: Scatter 3D plot of Pareto population showing the global desirability into the objective space: desirability $(D)$ versus adsorption capacity $(\widehat{q})$ and color removal efficiency $(\widehat{Y})$.

from Pareto population. Figure 12 shows the scatter 3D plot of Pareto population into the desirability-objectives space. A maximum value of desirability $(D=0.7958)$ is attained for $\widehat{Y}=93.894$ and $\widehat{q}=7.290$. This point has been selected as the optimal solution for experimental confirmation. The results of confirmation run are reported in Table 9. The optimum conditions in terms of controllable variables are $t^{*}=152 \mathrm{~min}$, $C_{0}^{*}=39 \mathrm{mg} / \mathrm{L}$, and $\mathrm{SD}^{*}=4.59 \mathrm{~g} / \mathrm{L}$. The responses confirmed by experiment under such conditions are $Y=94.579(\%)$ and $q=6.450 \mathrm{mg} / \mathrm{g}$.
The comparisons of the results from single and multiobjective optimization strategies reveal that the removal efficiency, for case 2 , is smaller with $4.5 \%$. In turn, the adsorption capacity is about 3-fold higher. The optimal solution derived from single-objective optimization (case 1) is more suitable if the aim of decontamination is to obtain the maximal removal efficiency. The optimum point determined by multiobjective strategy (case 2) is more appropriate for the enhanced adsorption accomplished in a shorter time and with a smaller sorbent amount.

\section{Conclusions}

In this work, the nanosized spinel ferrites $\mathrm{MFe}_{2} \mathrm{O}_{4}(\mathrm{M}=$ $\mathrm{Ni}$, Co, and $\mathrm{Zn}$ ) were obtained by sol-gel autocombustion method. The XRD analysis and FTIR spectroscopy confirmed the pure spinel phase formation for all the ferrite samples sintered at $973 \mathrm{~K}$. The presence of nanometric particles and a low degree of agglomeration were observed by TEM.

The obtained ferrite materials were applied for CongoRed (CR) adsorption from aqueous solutions. The screening test revealed that the most efficient adsorbents for $\mathrm{CR}$ removal were $\mathrm{NiFe}_{2} \mathrm{O}_{4}$ followed by $\mathrm{CoFe}_{2} \mathrm{O}_{4}$. The adsorption kinetics disclosed that the data were best fitted by $\mathrm{PnO}$ model, suggesting that the most appropriate orders for the rate equations were $n=1.654$ (for $\mathrm{NiFe}_{2} \mathrm{O}_{4}$ ) and $n=2.556$ (for $\mathrm{CoFe}_{2} \mathrm{O}_{4}$ ). The Freundlich isotherm model showed the best agreement with the experimental data, suggesting the heterogeneous adsorption of CR onto magnetic sorbents. The maximum adsorption capacity at $293 \mathrm{~K}$ was $14.06 \mathrm{mg} / \mathrm{g}$ for $\mathrm{CoFe}_{2} \mathrm{O}_{4}$ and $17.13 \mathrm{mg} / \mathrm{g}$ for $\mathrm{NiFe}_{2} \mathrm{O}_{4}$. The values of mean 
free energy $E_{S}$ determined from Dubinin-Radushkevich (D$\mathrm{R}$ ) isotherm suggested the chemical adsorption mechanism.

The response surface methodology was employed for modeling and optimization of the process to enhance CR adsorption onto $\mathrm{NiFe}_{2} \mathrm{O}_{4}$. The optimum point resulted from single-objective optimization was confirmed by experiment giving the maximal value of color removal efficiency of $Y=$ 98.995\%. The multiobjective optimization done by NSGA-II and DFA methods led to the improved values of both color removal efficiency and adsorption capacity, that is, $94.579 \%$ and $6.45 \mathrm{mg} / \mathrm{g}$, respectively.

\section{Conflict of Interests}

The authors declare no conflict of interests.

\section{Authors' Contribution}

Petrisor Samoila was responsible for preparing and characterization of nanosized spinel ferrites as well as their application on adsorption experiments; Corneliu Cojocaru did adsorption experiments, kinetic, equilibrium, and thermodynamic analysis, experimental design, and modeling and optimization computation; Igor Cretescu contributed to the data analysis, optimization, and managed results development; Catalina Daniela Stan contributed to statistical data analysis and FTIR interpretation; Valentin Nica was responsible for XRD analysis; Liviu Sacarescu was responsible for TEM analysis; Valeria Harabagiu coordinated the research tasks in the paper. All authors read and approved the final paper.

\section{References}

[1] D. V. Kerkez, D. D. Tomasevic, G. Kozma et al., "Three different clay-supported nanoscale zero-valent iron materials for industrial azo dye degradation: a comparative study," Journal of the Taiwan Institute of Chemical Engineers, vol. 45, no. 5, pp. 2451-2461, 2014.

[2] S. Saroj, K. Kumar, N. Pareek, R. Prasad, and R. P. Singh, "Biodegradation of azo dyes acid red 183, direct blue 15 and direct red 75 by the isolate Penicillium oxalicum SAR-3," Chemosphere, vol. 107, pp. 240-248, 2014.

[3] S. K. Vishwakarma, M. P. Singh, A. K. Srivastava, and V. K. Pandey, "Azo dye (direct blue 14) decolorization by immobilized extracellular enzymes of Pleurotus species," Cellular and Molecular Biology, vol. 58, no. 1, pp. 21-25, 2012.

[4] M. Sudha, A. Saranya, G. Selvakumar, and N. Sivakumar, "Microbial degradation of azo dyes: a review," International Journal of Current Microbiology and Applied Sciences, vol. 3, no. 2, pp. 670-690, 2014.

[5] E. Forgacs, T. Cserháti, and G. Oros, "Removal of synthetic dyes from wastewaters: a review," Environment International, vol. 30, no. 7, pp. 953-971, 2004.

[6] J. Vijayaraghavan, S. J. S. Basha, and J. Jegan, "A review on efficacious methods to decolorize reactive azo dye," Journal of Urban and Environmental Engineering, vol. 7, no. 1, pp. 30-47, 2013.

[7] I. Khosravi and M. Eftekhar, "Characterization and evaluation catalytic efficiency of $\mathrm{NiFe}_{2} \mathrm{O}_{4}$ nano spinel in removal of reactive dye from aqueous solution," Powder Technology, vol. 250, pp. 147-153, 2013.

[8] W. Konicki, D. Sibera, E. Mijowska, Z. Lendzion-Bieluń, and U. Narkiewicz, "Equilibrium and kinetic studies on acid dye Acid Red 88 adsorption by magnetic $\mathrm{ZnFe}_{2} \mathrm{O}_{4}$ spinel ferrite nanoparticles," Journal of Colloid and Interface Science, vol. 398, pp. 152-160, 2013.

[9] L. Wang, J. Li, Y. Wang, L. Zhao, and Q. Jiang, "Adsorption capability for Congo red on nanocrystalline $\mathrm{MFe}_{2} \mathrm{O}_{4}(\mathrm{M}=\mathrm{Mn}$, $\mathrm{Fe}, \mathrm{Co}, \mathrm{Ni}$ ) spinel ferrites," Chemical Engineering Journal, vol. 181-182, pp. 72-79, 2012.

[10] R. Wu and J. Qu, "Removal of water-soluble azo dye by the magnetic material $\mathrm{MnFe}_{2} \mathrm{O}_{4}$," Journal of Chemical Technology and Biotechnology, vol. 80, no. 1, pp. 20-27, 2005.

[11] L. Zhang, J. Lian, L. Wang, J. Jiang, Z. Duan, and L. Zhao, "Markedly enhanced coercive field and Congo red adsorption capability of cobalt ferrite induced by the doping of nonmagnetic metal ions," Chemical Engineering Journal, vol. 241, pp. 384-392, 2014.

[12] P. Samoila, T. Slatineanu, P. Postolache, A. R. Iordan, and M. N. Palamaru, "The effect of chelating/combustion agent on catalytic activity and magnetic properties of Dy doped Ni-Zn ferrite," Materials Chemistry and Physics, vol. 136, no. 1, pp. 241246, 2012.

[13] K. A. Tan, N. Morad, T. T. Teng, I. Norli, and P. Panneerselvam, "Removal of cationic dye by magnetic nanoparticle $\left(\mathrm{Fe}_{3} \mathrm{O}_{4}\right)$ impregnated onto activated maize cob powder and kinetic study of dye waste adsorption," APCBEE Procedia, vol. 1, pp. 83-89, 2012.

[14] M.-X. Zhu, L. Lee, H.-H. Wang, and Z. Wang, "Removal of an anionic dye by adsorption/precipitation processes using alkaline white mud," Journal of Hazardous Materials, vol. 149, no. 3, pp. 735-741, 2007.

[15] T. Slatineanu, E. Diana, V. Nica et al., "The influence of the chelating/combustion agents on the structure and magnetic properties of zinc ferrite," Central European Journal of Chemistry, vol. 10, no. 6, pp. 1799-1807, 2012.

[16] Y.-S. Ho, "Citation review of Lagergren kinetic rate equation on adsorption reactions," Scientometrics, vol. 59, no. 1, pp. 171-177, 2004.

[17] S. Lagergren, "Zur theorie der sogenannten adsorption geloster stoffe, Kungliga Svenska Vetenskapsakademiens," Handlingar, vol. 24, no. 4, pp. 1-39, 1898.

[18] Y. S. Ho, "Second-order kinetic model for the sorption of cadmium onto tree fern: a comparison of linear and non-linear methods," Water Research, vol. 40, no. 1, pp. 119-125, 2006.

[19] S. Azizian and R. N. Fallah, "A new empirical rate equation for adsorption kinetics at solid/solution interface," Applied Surface Science, vol. 256, no. 17, pp. 5153-5156, 2010.

[20] A. Özer, "Removal of $\mathrm{Pb}(\mathrm{II})$ ions from aqueous solutions by sulphuric acid-treated wheat bran," Journal of Hazardous Materials, vol. 141, no. 3, pp. 753-761, 2007.

[21] R. N. Fallah and S. Azizian, "Removal of thiophenic compounds from liquid fuel by different modified activated carbon cloths," Fuel Processing Technology, vol. 93, no. 1, pp. 45-52, 2012.

[22] A. W. Marczewski, "Application of mixed order rate equations to adsorption of methylene blue on mesoporous carbons," Applied Surface Science, vol. 256, no. 17, pp. 5145-5152, 2010.

[23] M. Constantin, I. Asmarandei, V. Harabagiu, L. Ghimici, P. Ascenzi, and G. Fundueanu, "Removal of anionic dyes from aqueous solutions by an ion-exchanger based on pullulan 
microspheres," Carbohydrate Polymers, vol. 91, no. 1, pp. 74-84, 2013.

[24] W. J. Weber and J. C. Morris, "Kinetics of adsorption on carbon from solution," Journal of the Sanitary Engineering DivisionAmerican Society of Civil Engineers, vol. 89, pp. 31-60, 1963.

[25] M. C. Ncibi, "Applicability of some statistical tools to predict optimum adsorption isotherm after linear and non-linear regression analysis," Journal of Hazardous Materials, vol. 153, no. 1-2, pp. 207-212, 2008.

[26] H. M. F. Freundlich, "Over the adsorption in solution," The Journal of Physical Chemistry, vol. 57, pp. 385-470, 1906.

[27] B. Yahyaei and S. Azizian, "Rapid adsorption of anionic dyes by ordered nanoporous alumina," Chemical Engineering Journal, vol. 209, pp. 589-596, 2012.

[28] Y. S. Ho, C. T. Huang, and H. W. Huang, "Equilibrium sorption isotherm for metal ions on tree fern," Process Biochemistry, vol. 37, no. 12, pp. 1421-1430, 2002.

[29] I. Langmuir, "The constitution and fundamental properties of solids and liquids. Part I. Solids," The Journal of the American Chemical Society, vol. 38, no. 2, pp. 2221-2295, 1916.

[30] D.-P. Li, Y.-R. Zhang, X.-X. Zhao, and B.-X. Zhao, "Magnetic nanoparticles coated by aminoguanidine for selective adsorption of acid dyes from aqueous solution," Chemical Engineering Journal, vol. 232, pp. 425-433, 2013.

[31] N. Ünlü and M. Ersoz, "Removal of heavy metal ions by using dithiocarbamated-sporopollenin," Separation and Purification Technology, vol. 52, no. 3, pp. 461-469, 2007.

[32] S. Akhnazarova and V. Kafarov, Experiment Optimization in Chemistry and Chemical Engineering, Mir Publishers, Moscow, Russia, 2nd edition, 1982.

[33] M. A. Bezerra, R. E. Santelli, E. P. Oliveira, L. S. Villar, and L. A. Escaleira, "Response surface methodology (RSM) as a tool for optimization in analytical chemistry," Talanta, vol. 76, no. 5, pp. 965-977, 2008.

[34] D. C. Montgomery, Design and Analysis of Experiments, John Wiley \& Sons, New York, NY, USA, 5th edition, 2001.

[35] X. Blasco, J. M. Herrero, J. Sanchis, and M. Martínez, "A new graphical visualization of $n$-dimensional Pareto front for decision-making in multiobjective optimization," Information Sciences, vol. 178, no. 20, pp. 3908-3924, 2008.

[36] K. Deb, A. Pratap, S. Agarwal, and T. Meyarivan, "A fast and elitist multiobjective genetic algorithm: NSGA-II," IEEE Transactions on Evolutionary Computation, vol. 6, no. 2, pp.182197, 2002.

[37] N. R. Costa, J. Lourenço, and Z. L. Pereira, "Desirability function approach: a review and performance evaluation in adverse conditions," Chemometrics and Intelligent Laboratory Systems, vol. 107, no. 2, pp. 234-244, 2011.

[38] M. S. Secula, C. S. Stan, C. Cojocaru, B. Cagnon, and I. Cretescu, "Multi-objective optimization of indigo carmine removal by an electrocoagulation/GAC coupling process in a batch reactor," Separation Science and Technology, vol. 49, no. 6, pp. 924-938, 2014. 

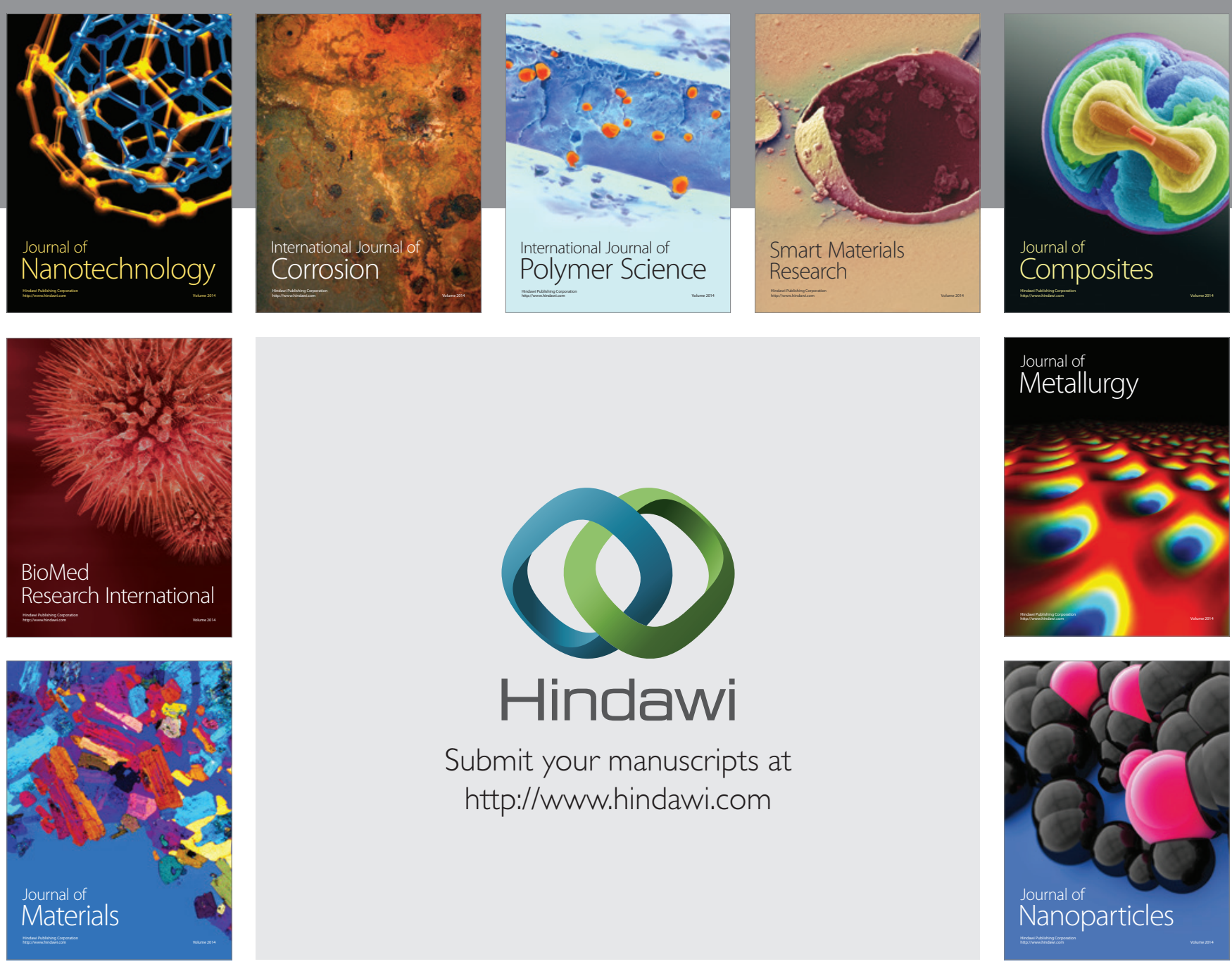

Submit your manuscripts at http://www.hindawi.com
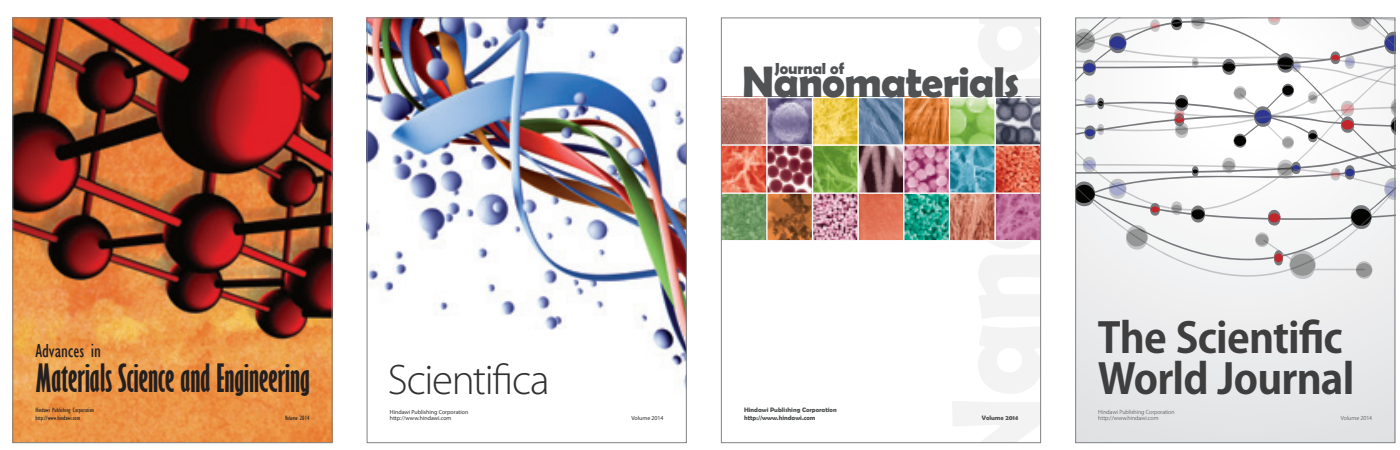

\section{The Scientific World Journal}
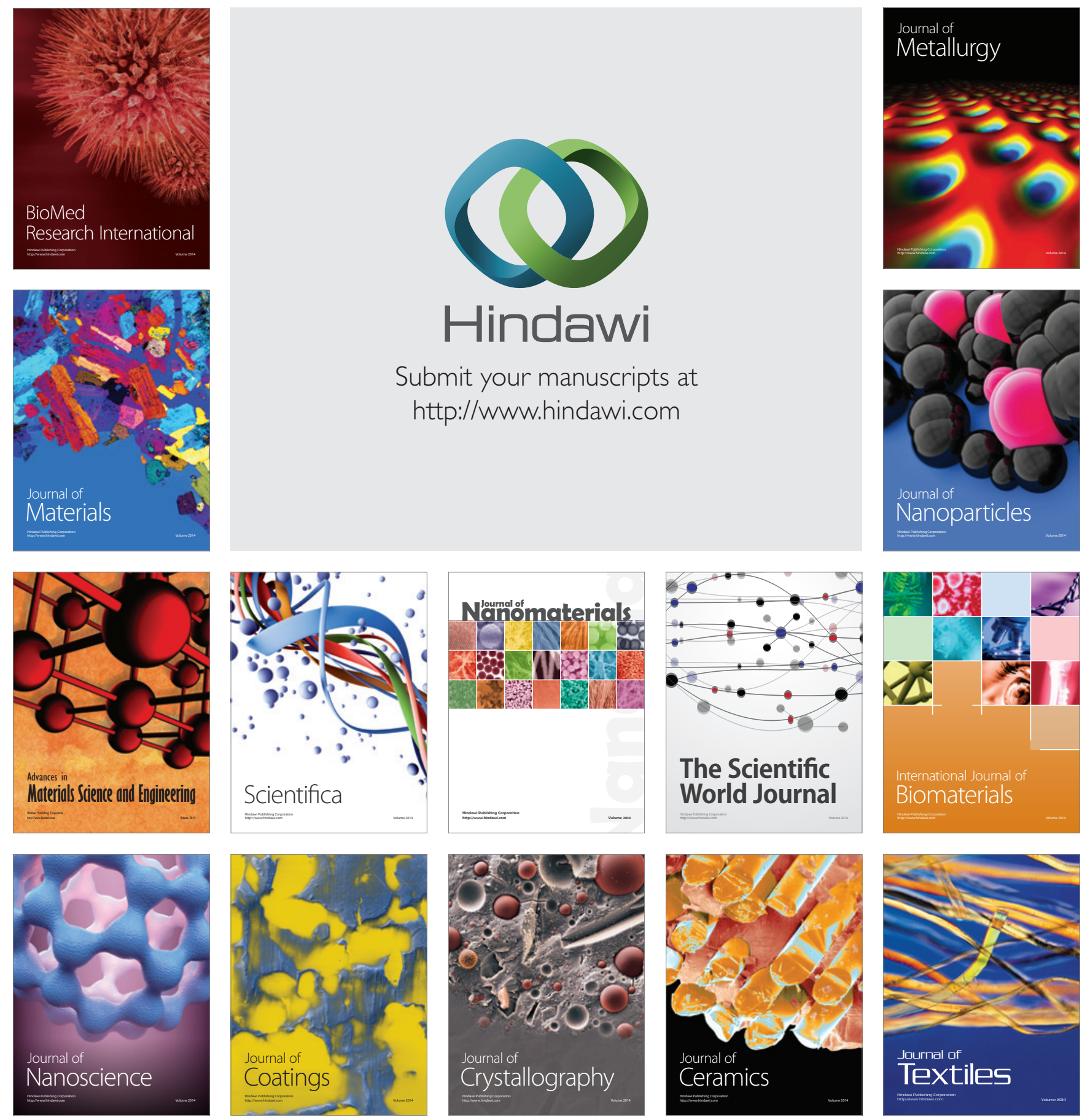